\title{
On the parameterisation of oceanic sensible heat loss to the atmosphere and to ice in an ice-covered mixed layer in winter
}

\section{Bert Rudels ${ }^{\mathrm{a}, *}$, Hans J. Friedrich ${ }^{\mathrm{b}}$, Dagmar Hainbucher ${ }^{\mathrm{b}}$, Gerrit Lohmann ${ }^{\mathrm{c}}$}

\author{
${ }^{a}$ Finnish Institute of Marine Research, PL33, FIN-00931 Helsinki, Finland \\ ${ }^{\mathrm{b}}$ Institut für Meereskunde der Universität Hamburg, Troplowitzstraße 7, D-22529 Hamburg, Germany \\ 'Alfred Wegener Institut für Polar- und Meeresforschung, Postfach 120161, D-27515, Bremerhaven, Germany
}

Received 11 February 1998; received in revised form 3 November 1998; accepted 5 November 1998

\begin{abstract}
In high-latitude oceans with seasonal ice cover, the ice and the low-salinity mixed layer form an interacting barrier for the heat flux from the ocean to the atmosphere. The presence of a less dense surface layer allows ice to form, and the ice cover reduces the heat loss to the atmosphere. The ice formation weakens the stability at the base of the mixed layer, leading to stronger entrainment and larger heat flux from below. This heat transport retards, and perhaps stops, the growth of the ice cover. As much heat is then entrained from below as is lost to the atmosphere. This heat loss further reduces the stability, and unless a net ice melt occurs, the mixed layer convects. Two possibilities exist: (1) A net ice melt, sufficient to retain the stability, will always occur and convection will not take place until all ice is removed. The deep convection will then be thermal, deepening the mixed layer. (2) The ice remains until the stability at the base of the mixed layer disappears. The mixed layer then convects, through haline convection, into the deep ocean. Warm water rises towards the surface and the ice starts to melt, and a new mixed layer is reformed. The present work discusses the interactions between ice cover and entrainment during winter, when heat loss to the atmosphere is present. One crucial hypothesis is introduced: "When ice is present and the ocean loses sensible heat to the atmosphere and to ice melt, the buoyancy input at the sea surface due to ice melt is at a minimum". Using a onedimensional energy-balance model, applied to the artificial situation, where ice melts directly on warmer water, it is found that this corresponds to a constant fraction of the heat loss going to ice melt. It is postulated that this partitioning holds for the ice cover and the mixed layer in the high-latitude ocean. When a constant fraction of heat goes to ice melt, at least one deep
\end{abstract}

* Corresponding author. Fax: 00358-9-331-025.

E-mail address: rudels@fimr.fi (B. Rudels) 
convection event occurs, before the ice cover can be removed by heat entrained from below. After one or several convection events the ice normally disappears and a deep-reaching thermal convection is established. Conditions appropriate for the Weddell Sea and the Greenland Sea are examined and compared with field observations. With realistic initial conditions no convection occurs in the warm regime of the Weddell Sea. A balance between entrained heat and atmospheric heat loss is established and the ice cover remains throughout the winter. At Maud Rise convection may occur, but late in winter and normally no polynya can form before the summer ice melt. In the central Greenland Sea the mixed layer generally convects early in winter and the ice is removed by melting from below as early as February or March. This is in agreement with existing observations. (C) 1999 Elsevier Science Ltd. All rights reserved.

\section{Introduction}

High-latitude oceans in both hemispheres are covered with sea ice. Part of the ice cover is perennial, surviving the summer, but most of it is seasonal, forming in fall and disappearing the following summer. The fraction of permanent ice cover is largest in the Arctic, where the ratio of minimum to maximum ice cover extent is about $1 / 2$. In the southern ocean only $1 / 5$ of the winter ice cover survives the following summer. This difference is mainly due to the confined geography of the Arctic Ocean, which restricts the export of ice to lower latitudes, where the ice diverges and where a stronger input of sensible heat from the underlying ocean is present. If the ice drifts into warmer water, this heat could come directly from the ocean. It also could be due to a larger presence of leads in a diverging ice cover, allowing the solar radiation to become absorbed in the water column. A second factor, acting to preserve the ice cover in the Arctic Ocean, is the strong stratification of the water column due to the low-salinity Polar Mixed Layer and the intermediate, cold halocline. The presence of the halocline over a large part of the Arctic Ocean leads to entrainment of colder water. Should the mixed layer deepen by freezing and haline convection during winter, no heat is added, reducing the ice formation. The limiting factor for the ice growth is the ice thickness, which diminishes the heat loss to the atmosphere.

In the Greenland Sea, as also in the Weddell Sea, ice has been observed to disappear in late winter, when heat loss to the atmosphere still occurs and no input of short wave radiation is present. In the Greenland Sea this has been partly attributed to winds removing the ice. However, in some instances the removal has been so rapid that melting, caused by sensible heat supplied from below, is a more probable explanation. This is also likely for the Weddell Sea polynya, which was observed in late winter in the mid-1970s (Zwally et al., 1983). The observation of a deep (>4000 m), homogenous water column in the following summer suggested that the polynya had either been preceded by, or been the cause of, deep reaching convection (Gordon, 1978).

The water columns in the central Greenland and Weddell Seas are weakly stratified, and a cold, less saline surface layer rides on top of warmer, more saline water. A reservoir of sensible heat is close and may be tapped in winter. That this heat is not immediately available is clear from the fact that the cooling in autumn leads to 
freezing temperature and ice formation. Not until late in winter will the heat flux from the underlying water become large enough to start to melt the ice. The stratification in fall thus prevents the heat flux from below from balancing the heat lost to the atmosphere, and ice must form. Freezing leads to brine rejection. The density of the surface layer increases, and the stability of the water column decreases. The growth of the ice cover reduces the heat loss to the atmosphere, and if the initial stratification of the water column is sufficiently weak, the heat flux from below may increase sufficiently to balance the heat lost to the atmosphere and stop further ice growth. The subsequent disappearance of the ice in weakly stratified areas, and the deep almost homogenous water columns observed in spring suggest that convection has taken place. A convective removal of the upper layer would bring warm water into contact with the ice cover and cause the ice to melt, and perhaps to disappear. Such convection, since the mixed layer is at freezing temperature, has to be haline.

However, Backhaus (1995), applying a non-hydrostatic convection model for haline convection in the Greenland Sea, found that as the stability decreases, plumes reaching the lower boundary of the mixed layer would induce such strong entrainment of warmer water into the mixed layer that it would practically inhibit the ice formation and the generation of saline, dense plumes. The convection would become weaker and the deepening of the mixed layer would stop. Backhaus then suggested that the ice has to be largely removed by wind before a deeper-reaching, thermal convection could be established. Observations of convection occurring in regions where no mechanically induced shear is present have normally indicated less energetic entrainment. The mixed layer becomes homogenised by the convection, but the entrainment due to convection is significantly smaller than that caused by windgenerated turbulence (Farmer, 1975). The strong vertical heat flux obtained by Backhaus (1995) could be due to the use of a non-hydrostatic convection model, which leads to larger vertical displacements as the sinking plumes impinge upon the stable interface at the bottom of the mixed layer.

In most mixed-layer models it is assumed that turbulent entrainment caused by wind is significantly larger than that due to convection, and Walin (1993) studied the effects of wind-induced turbulence on the ice cover and the entrainment. Adopting a simple energy balance model (Niiler and Kraus, 1977) he assumed that the development of the high-latitude mixed layer in winter could be considered in two idealised stages. In the first stage there is little (no) entrainment, and the salinity (and density) of the mixed layer increases due to freezing and brine rejection. In the second phase the stability has been lowered sufficiently for a "freeze-melting" state to be attained, where heat entrained from below supplies all the heat lost to the atmosphere. Heat is also available to melt enough ice to keep the upper layer stable as it deepens. Given a long enough winter the ice would eventually disappear. The stabilising freshwater input is then gone and the upper layer convects, thermally, to great depths. In the Weddell Sea, which was the focus of Walin's discussion, the duration of the freezemelting period has to be significantly longer than the span of the winter to remove the ice, and the ice cover would normally remain and melt the following summer. Visbeck et al. (1995) applied a similar model to the Greenland Sea. They derived a similar pattern of ice growth and melting and, assuming a partial export of the ice 
cover, a situation arose where the ice disappeared and the mixed layer deepened rapidly.

The results from these studies then imply: (1) Deep haline convection is not possible, because heat entrained from below will inhibit the ice formation; (2) ice is removed by melting and/or exported before deep convection occurs; (3) all deep convection in the ocean is thermal.

For one of us (BR), being a supporter of the idea that deep haline convection is the most important process for triggering the deep convection events forming the Greenland Sea Deep Water (Rudels, 1990,1993), and perhaps also the deep, vertically homogenous water column associated with the Weddell Sea polynya, these are disturbing results. Before any fruitless efforts on describing haline deep convection are made, the effects of the heat flux from the underlying ocean on the evolution of the mixed layer, on the entrainment, and on the ice cover, must be considered. Following conventional wisdom, we assume that wind stirring is more efficient in entraining water into the mixed layer and thereby concentrate on the effects of mechanically generated entrainment on the ice growth and do not study the strongly convective situation considered by Backhaus (1995).

The formulation of the buoyancy flux used by Walin (1993) and Visbeck et al. (1995) is different from the one applied by Lemke (1987), Lemke et al. (1990), Houssais (1988) and Houssais and Hibler (1993). Walin (1993) balances entrained heat with heat lost to the atmosphere. If it is smaller, ice is formed. If it is greater, ice melts. In the first phase all entrained heat goes directly to the atmosphere; in the second, freeze-melting phase, no new ice is formed although the mixed layer is at freezing temperature. The entrainment is sufficiently strong to provide, directly, all heat to the atmosphere and some additional heat to melt ice. This freshwater input is necessary to maintain the stratification and to prevent the mixed layer from overturning.

By contrast, Lemke (1987) allows all heat entrained into the mixed layer to go to melting. The heat lost to the atmosphere is balanced by ice formation, in leads and under the ice floes. The buoyancy flux then has two contributions, one positive due to ice melt and related to the entrainment from below, and one negative from ice formation, determined by the heat loss to the atmosphere. This separation does not change the ice balance or the stability at the base of the mixed layer. However, if entrainment caused by convection is weaker than that due to wind generated turbulence, the reduced entrainment, which results from increased melting, cannot be balanced by entrainment driven by haline convection. The heat flux into the mixed layer from below will be smaller and more ice must form to balance the heat loss to the atmosphere.

Lemke (1987) and Houssais (1988) do not explicitly address the effects of entrainment upon the ice cover and of ice melt upon the entrainment. Lemke (1987) considered primarily the situation in the Arctic Ocean, but in a later work (Lemke et al., 1990) exponential profiles for vertical temperature and salinity distributions beneath the mixed layer were used from the Weddell Sea. This means that deepening but no overturning occurs, and the issue of net melting providing the buoyancy input needed to keep the stratification, and the mixed layer, does not arise. Houssais (1988) and Houssais and Hibler (1993) studied the Greenland Sea, and Houssais (1988) found 
that the deepest convection, down to $3000 \mathrm{~m}$ in some cases, occurs in the ice-free area in the central Greenland Sea. However, it is difficult to determine from her figures, if the ice edge is controlled by entrainment and melting of the ice by heat from below, or if it is related to the initial distribution of low-salinity surface water.

Which formulation is the most realistic one? For the melt water to inhibit the entrainment effectively, it must be mixed away from the ice into the mixed layer. A melting and subsequent freezing within the ice cover would not lead to a buoyancy flux. We therefore expect that some, but not all, entrained heat will go directly to the atmosphere without causing any melt water to enter the mixed layer. This fraction would be somewhere between the 0 of the Lemke (1987) formulation and the 1, which holds for the first phase in the model by Walin (1993), when the heat loss to the atmosphere is larger than the heat flux from below. If the situation arises that the heat flux from below is larger than the heat loss to the atmosphere, as in the freeze-melt stage (Walin, 1993), we still expect ice to form. When the ice cover becomes thinner and less compact, the likelihood for new ice formation may increase, even if there is a net ice melt. To balance the heat fluxes, more than the excess entrained heat will go to ice melt.

We propose a rationale for determining the distribution of the loss of oceanic sensible heat to ice melt and to the atmosphere. We assume that the entrainment can be described by an energy balance equation similar to the one used by Walin (1993). As with Walin (1993) the dissipation of the energy is taken to be independent of the depth of the mixed layer, although an exponential decay, like the one used by Houssais (1988), probably is more realistic. This would, however, bias our work against entrainment and make comparison with, e.g. Walin (1993) more difficult. For the same reason, as well as for simplicity, we assume an idealised two-layer ocean with an homogeneous mixed layer and an homogeneous deep ocean. The turbulent diffusion through the pycnocline is considered weak compared to the entrainment and is ignored. These assumptions also favour entrainment compared to the case with a stratified deep ocean (Lemke et al., 1990).

Only the cooling situation, with a cold, windy atmosphere above the ocean, is considered and we introduce the following hypothesis: When ice is present and the ocean loses sensible heat both to the atmosphere and to ice melt, the heat loss is so distributed that the buoyancy input at the sea surface due to ice melt is at a minimum. This holds regardless of the compactness and the thickness of the ice cover as long as it is horizontally homogeneous and the situation can be viewed as one-dimensional.

The hypothesis implies that the smallest possible part of the mechanical energy imparted to the mixed layer by the wind will go to stirring melt water into the mixed layer. Consequently the largest possible amount will be available for entrainment. The hypothesis thus maximises the flux of oceanic sensible heat to the mixed layer. Optimising methods have been used in several aspects of physics. We are well aware that its use here cannot be compared to the variational principles generally applied in mechanics. However, nature often seems to approach some optimal state. The problem is to understand what is being optimised. Be that as it may, at a more profane level, an extremum singles out one value among an infinity of possible ones and thus 
provides one reason for choosing this value. It is, at least in one respect, different from all the rest.

To find the partitioning for which the ice melt is a minimum, we must examine a situation where no latent heat of freezing enters the heat balance. We therefore consider a thought experiment: Ice is placed on top of a vertically homogeneous water column with temperature above freezing. Heat is lost by the ocean to the atmosphere and to ice melt. The melt water is stirred into the water column, and an upper mixed layer begins to form. The fraction of heat going to ice melt, which produces the smallest buoyancy input, can then be determined (Section 2.1). Section 2.2 then considers a situation like the one encountered in the Greenland Sea, where a less saline surface layer, lying above warmer water, is brought to freezing temperature in autumn and ice starts to form. The heat entrained into the upper layer from below is assumed distributed according to the partitioning obtained in Section 2.1. If cooling, freezing and brine release should remove the density step at the base of the mixed layer before the ice is melted, convection will bring the water of the mixed layer into the deep ocean. Warm water rises to the surface, ice starts to melt and a new mixed layer forms. Note that if the ice melts before the stability is gone, as was found by Walin (1993), this convection will not happen. Only situations with heat loss to the atmosphere are considered, and Section 3 describes the parameterisations of the heat loss and the evolution of the mixed layer which are used, and the effects of different forcing and stratification in some idealised cases before the situations in the Weddell Sea (Section 4.2) and the Greenland Sea (Section 4.3) are then considered.

\section{Ice melt, ice formation, entrainment and convection}

\subsection{Ice melting on warmer water}

Assume heat loss to the atmosphere, an horizontally homogeneous ice field, and apply an one-dimensional model for the water column. The salt and heat fluxes at the upper boundary of the ocean are

$$
\begin{aligned}
& \left.\overline{w^{\prime} S^{\prime}}\right|_{z=0}=-\frac{\rho_{\mathrm{i}}}{\rho_{\mathrm{w}}} M_{1}\left(S-S_{i}\right)+\frac{\rho_{\mathrm{i}}}{\rho_{\mathrm{w}}} F_{1}\left(S-S_{i}\right)+\frac{\rho_{0}}{\rho_{\mathrm{w}}} E S-\frac{\rho_{0}}{\rho_{\mathrm{w}}} P S, \\
& \left.\overline{w^{\prime} T^{\prime}}\right|_{z=0}=-\frac{Q}{\rho_{\mathrm{w}} c}=-\frac{1}{\rho_{\mathrm{w}} c}\left\{Q_{\mathrm{sa}}+\rho_{\mathrm{i}} M_{1}\left[L+c\left(T-T_{\mathrm{f}}\right)\right]\right\} .
\end{aligned}
$$

$T$ and $S$ are the temperature and salinity at the sea surface, $M_{1}$ is ice melted, $F_{1}$ is ice formed, $E$ and $P$ denote evaporation and precipitation, $S_{i}$ is the salinity of sea ice and $T_{f}$ the freezing temperature, $\rho_{0}, \rho_{\mathrm{i}}$ and $\rho_{\mathrm{w}}$ are the densities of freshwater, ice and sea water, respectively, $Q$ is the loss of sensible heat by the ocean and $Q_{\mathrm{sa}}$ is the part going to atmosphere and space, which includes fluxes of sensible heat and latent heat of evaporation and net long wave radiation. We consider a winter situation and contributions from short-wave radiation are ignored. $L$ is the latent heat of melting, and $c$ the specific heat of sea water. 
To concentrate on the partitioning of the oceanic heat loss we make some simplifications. Precipitation and evaporation are ignored in the salt balance. The sensible heat stored in the ice and the heat capacity of the melt water are considered small and neglected compared with the latent heat of melting. In most situations the mean ice temperature is about $-10^{\circ}$, and the sensible heat in the ice amounts to $5 \%$ of the latent heat of melting. If the temperature of the ocean is $1-2^{\circ} \mathrm{C}$ above freezing, the heat needed to rise the temperature of the melt water by this amount corresponds to $2 \%$ of the heat needed to melt the corresponding amount of ice. This assumption means that the melt water immediately attains the mixed-layer temperature.

We are interested in freshwater added or removed, and since the latent heat of melting in sea ice decreases with increasing salinity (Defant, 1961), the effects of freezing or melting on the salinity of the water column are largely independent of the assumed salinity of the ice. $S_{\mathrm{i}}$ is therefore set to zero, and we introduce the freshwater fluxes $M=\rho_{\mathrm{i}} \rho_{0}^{-1} M_{1}$ and $F=\rho_{\mathrm{i}} \rho_{0}^{-1} F_{1}$ and make the approximation $\rho_{0}=\rho_{w}=\rho=1000 \mathrm{~kg} \mathrm{~m}^{-3}$.

In the present thought experiment the temperature of the water column is above freezing. Since the controversy between Fridtjof Nansen and Otto Petersson at the turn of the century (Gade, 1993), it has been commonly accepted that ice melting on warmer water creates a less saline, colder and less dense surface layer, also if heat is simultaneously lost to the atmosphere (Fig. 1). We assume that sufficient wind stirring is present to homogenise this developing surface layer and that the entrainment from
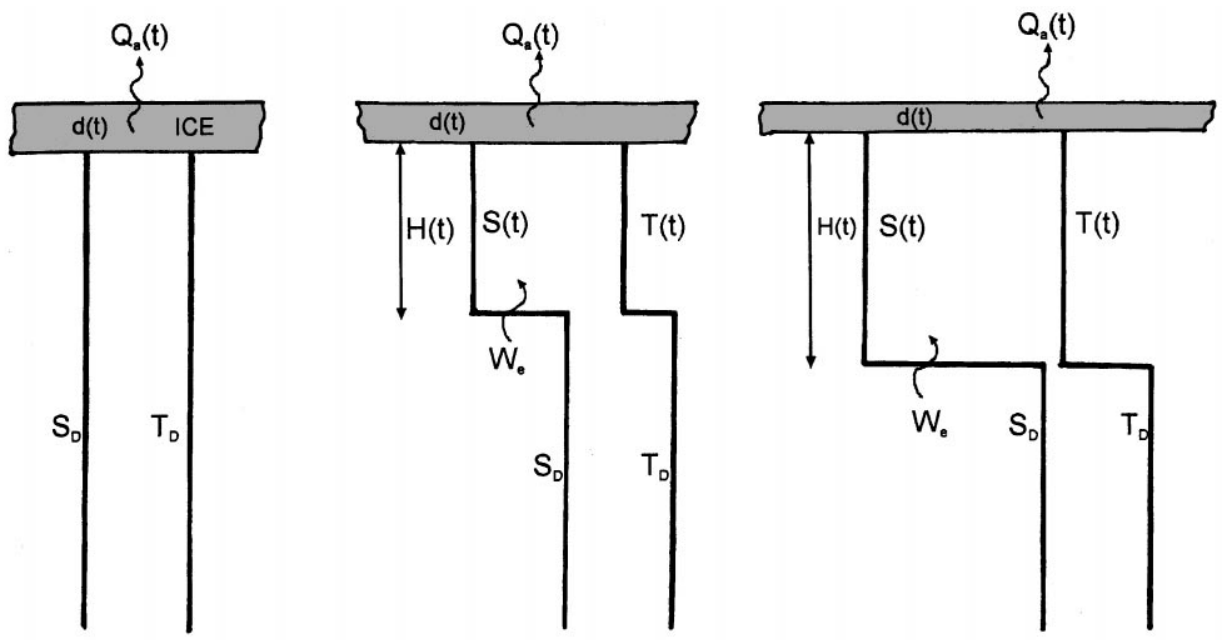

time

Fig. 1. The evolution of the temperature and salinity profiles as a mixed layer develops out of a homogeneous warmer water column. The profiles are scaled as to show the magnitude of the density contributions. 
below can be described by a one-dimensional energy balance model. Keeping only turbulent stirring and the surface buoyancy input, the mechanical energy budget equation gives.

$$
w_{\mathrm{e}}=\operatorname{Max}\left\{\frac{2 m_{0} u_{*}^{3}}{g \Delta_{\mathrm{D}} \rho^{\prime} H}-\varepsilon \frac{B}{g \Delta_{\mathrm{D}} \rho^{\prime}} ; 0\right\}
$$

for the entrainment velocity at the bottom of the turbulent mixed layer (Niiler and Kraus, 1977). $\Delta_{\mathrm{D}}=(\quad)_{\mathrm{D}}-(\quad)$ is the difference in properties between the deep ocean $D$ and the mixed layer, $u_{*}$ is the friction velocity and the first term on the r.h.s. of (2) refers to stirring by the surface stress, $m_{0}$ is a dissipation factor and we adopt the laboratory value $=1.25$ (Kato and Phillips, 1969). The second term on the r.h.s. gives the effects of the buoyancy flux $B$ at the sea surface. We apply $\varepsilon=1$ for $B \geqslant 0$, but $\varepsilon=0.05$ for $B<0$; i.e. free convection is not very efficient in contributing to entrainment (Walin, 1993). In detrainment situations (2) gives $w_{\mathrm{e}}=0$.

For a linear equation of state, the buoyancy step at the base of the mixed layer is

$$
g \frac{\Delta_{\mathrm{D}} \rho}{\rho}=g \Delta_{\mathrm{D}} \rho^{\prime}=\Delta_{\mathrm{D}} b=g\left[\beta\left(S_{\mathrm{D}}-S\right)-\alpha\left(T_{\mathrm{D}}-T\right)\right],
$$

where $\alpha$ and $\beta$ are coefficients of heat expansion and salt contraction, respectively. The boundary conditions for temperature and salinity at the base of the mixed layer are:

$$
\left.\overline{w^{\prime}\left(T^{\prime}, S^{\prime}\right)}\right|_{z=-\mathrm{H}}=w_{\mathrm{e}}\left(\Delta_{\mathrm{D}} T, \Delta_{\mathrm{D}} S\right) .
$$

Mass continuity for the mixed layer gives

$$
\frac{\mathrm{d} H}{\mathrm{~d} t}=w_{\mathrm{e}}+M, \quad w_{\mathrm{e}} \geqslant 0 ;
$$

and with the approximations made above the temperature and salinity changes in the mixed layer become

$$
\begin{aligned}
& H \frac{\mathrm{d} T}{\mathrm{~d} t}=-\left(\frac{Q_{\mathrm{sa}}}{\rho c}+\frac{M L}{c}\right)+w_{\mathrm{e}} \Delta_{\mathrm{D}} T=-\frac{\{(1-f) Q+f Q\}}{\rho c}+w_{\mathrm{e}} \Delta_{\mathrm{D}} T, \\
& H \frac{\mathrm{d} S}{\mathrm{~d} t}=-M S+w_{\mathrm{e}} \Delta_{\mathrm{D}} S,
\end{aligned}
$$

where in (6) $f$ is the fraction of heat going to ice melt and $(1-f)$ is the part transferred to the atmosphere. According to our hypothesis $f$ must attain such a value that the buoyancy input;

$$
\left.g \beta \overline{w^{\prime} S^{\prime}}\right|_{Z=0}=g \beta M S=\frac{f Q}{\rho L} g \beta S
$$

is a minimum. Since $\rho, L, \beta$ and $S$ can be regarded as constants, it follows that $f Q$ must be a minimum. We assume that the $f=f_{0}$ for which the minimum occurs is constant for a given configuration and proceed to determine $f_{0}$. 
The density increase due to cooling is much smaller than the density decrease due to added melt water. We therefore do not expect that cooling leads to convection or generates any buoyancy-driven entrainment, when ice is present. Cooling, however, reduces the buoyancy input, and the net effect of cooling and melting is considered in the buoyancy flux $B$ the sea surface. When $T$ is above freezing, $B$ is given by

$$
B=g\left\{\left(w_{\mathrm{e}} \frac{f \mathcal{c}}{L} \Delta_{\mathrm{D}} T \beta S+\frac{f \mathcal{c}}{L} \beta S H \frac{\mathrm{d}\left(\Delta_{\mathrm{D}} T\right)}{\mathrm{d} t}\right)-\left(w_{\mathrm{e}} \alpha \Delta_{\mathrm{D}} T+H \alpha \frac{\mathrm{d}\left(\Delta_{\mathrm{D}} T\right)}{\mathrm{d} t}\right)\right\} .
$$

The first bracket on the right-hand side relates to the melting process, the second to cooling. In each bracket the first term arises from the entrainment of warmer water and the second from cooling the mixed layer.

The salinity $\mathrm{S}$ of the mixed layer develops according to

$$
S=\frac{S_{\mathrm{D}} \int_{0}^{t} w_{\mathrm{e}} \mathrm{d} t^{\prime}}{\int_{0}^{t}\left(w_{\mathrm{e}}+M\right) \mathrm{d} t^{\prime}},
$$

which, using the first bracket in Eq. (9), may be written as

$$
S=\frac{S_{\mathrm{D}} \int_{0}^{t} w_{\mathrm{e}} \mathrm{d} t^{\prime}}{\int_{0}^{t} w_{\mathrm{e}} \mathrm{d} t^{\prime}+\int_{0}^{t} w_{\mathrm{e}} f_{\mathcal{C}} / L \Delta_{\mathrm{D}} T \mathrm{~d} t^{\prime}+f_{\mathcal{C}} / L \int_{0}^{t} \mathrm{~d}\left(\Delta_{\mathrm{D}} T\right) / \mathrm{d} t \int_{0}^{t^{\prime}} w_{\mathrm{e}} \mathrm{d} t^{\prime \prime} \mathrm{d} t^{\prime}}
$$

where the neglect of the heat capacity of the melt water allows us to write $H=\int w_{\mathrm{e}} \mathrm{d} t$ in the last term in the denominator. Integrating by parts then gives

$$
S=\frac{S_{\mathrm{D}}}{\left(1+f c L^{-1} \Delta_{\mathrm{D}} T\right)} .
$$

Introducing the expressions for $B$ and $S$ into (3) leads to

$$
\begin{aligned}
w_{\mathrm{e}}= & \frac{2 m_{0} u_{*}^{3}}{\left.g\left\{\beta\left(S_{\mathrm{D}}-\frac{S_{\mathrm{D}}}{\left(1+f c L^{-1} \Delta_{\mathrm{D}} T\right.}\right)\right)-\alpha \Delta_{\mathrm{D}} T\right\} H} \\
& -\frac{g\left[\beta \frac{f c L^{-1} S_{\mathrm{D}}}{\left(1+f c L^{-1} \Delta_{\mathrm{D}} T\right)}\left(w_{\mathrm{e}} \Delta_{\mathrm{D}} T+H \frac{\mathrm{d}\left(\Delta_{\mathrm{D}} T\right)}{\mathrm{d} t}\right)-\alpha\left(w_{\mathrm{e}} \Delta_{\mathrm{D}} T+H \frac{\mathrm{d}\left(\Delta_{\mathrm{D}} T\right)}{\mathrm{d} t}\right)\right]}{g\left\{\beta\left(S_{\mathrm{D}}-\frac{S_{\mathrm{D}}}{\left(1+f c L^{-1} \Delta_{\mathrm{D}} T\right)}\right)-\alpha \Delta_{\mathrm{D}} T\right\}}
\end{aligned}
$$

for the entrainment velocity, which simplifies to

$$
w_{\mathrm{e}}=\frac{m_{0} u_{*}^{3}\left(1+f c L^{-1} \Delta_{\mathrm{D}} T\right)}{g \Delta_{\mathrm{D}} T\left(f c L^{-1} \beta S_{\mathrm{D}}-\alpha\left(1+f c L^{-1} \Delta_{\mathrm{D}} T\right)\right) H}-\frac{H}{2 \Delta_{\mathrm{D}} T} \frac{\mathrm{d}\left(\Delta_{\mathrm{D}} T\right)}{\mathrm{d} t} .
$$

The deepening of the surface mixed layer combines the entrainment of sea water from below and stirring of melt water from above according to

$$
\frac{\mathrm{d} H}{\mathrm{~d} t}=w_{\mathrm{e}}\left(1+\frac{f_{\mathcal{c}}}{L} \Delta_{\mathrm{D}} T\right)+\frac{f_{\mathcal{c}}}{L} H \frac{\mathrm{d}\left(\Delta_{\mathrm{D}} T\right)}{\mathrm{d} t} .
$$


When introducing Eq. (14), this gives

$$
\frac{\mathrm{d} H}{\mathrm{~d} t}=\frac{m_{0} u_{*}^{3}\left(1+f c L^{-1} \Delta_{\mathrm{D}} T\right)^{2}}{g \Delta_{\mathrm{D}} T\left(f c L^{-1} \beta S_{\mathrm{D}}-\alpha\left(1+f c L^{-1} \Delta_{\mathrm{D}} T\right)\right) H}-\frac{H\left(1-f_{c} L^{-1} \Delta_{\mathrm{D}} T\right)}{2 \Delta_{\mathrm{D}} T} \frac{\mathrm{d}\left(\Delta_{\mathrm{D}} T\right)}{\mathrm{d} t} .
$$

In the second term on the right hand side $H$ is reduced by the added fraction of melt water. As we neglect this contribution in the heat budget, we may write Eq. (16) as

$$
\frac{\mathrm{d}\left(H^{2} \Delta_{\mathrm{D}} T\right)}{\mathrm{d} t}=\frac{2 m_{0} u_{*}^{3}\left(1+f c L^{-1} \Delta_{\mathrm{D}} T\right)^{2}}{g\left(f c L^{-1} \beta S_{\mathrm{D}}-\alpha\left(1+f c L^{-1} \Delta_{\mathrm{D}} T\right)\right)} .
$$

In the bracket $\left(1+f c L^{-1} \Delta_{\mathrm{D}} T\right)$ the term $f_{c} L^{-1} \Delta_{\mathrm{D}} T$ is small $(\approx 0.01)$. We therefore neglect the time variation of $\Delta_{\mathrm{D}} T$ in $\left(1+f_{c} L^{-1} \Delta_{\mathrm{D}} T\right)$. The initial mixed layer depth is zero, and Eq. (17) integrates to

$$
H=\left(1+\frac{f_{c}}{L} \Delta_{\mathrm{D}} T\right) \sqrt{\frac{2 m_{0} u_{*}^{3} t}{g \Delta_{\mathrm{D}} T\left(f_{c} L^{-1} \beta S_{D}-\alpha\left(1+f c L^{-1} \Delta_{\mathrm{D}} T\right)\right)}} .
$$

Eq. (14) for the entrainment velocity, using the same approximation of $H$ as in the heat budget, then becomes

$$
w_{\mathrm{e}}=\sqrt{\frac{m_{0} u_{*}^{3}}{g \Delta_{\mathrm{D}} T}} *\left(\sqrt{\frac{1}{2 t}}-\frac{\sqrt{t}}{\sqrt{2} \Delta_{\mathrm{D}} T} \frac{\mathrm{d}\left(\Delta_{\mathrm{D}} T\right)}{\mathrm{d} t}\right) * \frac{1}{\sqrt{f c L^{-1} \beta S_{\mathrm{D}}-\alpha\left(1+f c L^{-1} \Delta_{\mathrm{D}} T\right)}}
$$

and the heat loss is given by

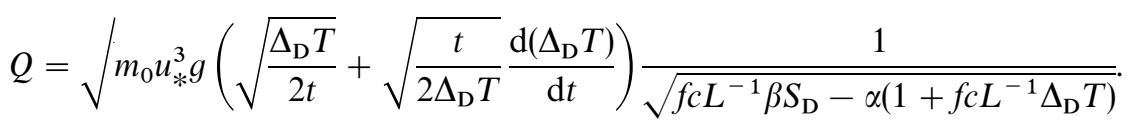

Within our approximations only the last factor contains $f$, and the requirement of minimum buoyancy input

$$
\mathrm{d}(f Q) / \mathrm{d} f=0
$$

then leads to

$$
f_{0}=\frac{2 \alpha L}{c\left(\beta S_{\mathrm{D}}-\alpha \Delta T\right)} .
$$

With values of $\alpha, \beta, \Delta_{\mathrm{D}} T$ and $S_{\mathrm{D}}$ representative for the high-latitude ocean $f_{0} \approx 0.23$. That is, about $\frac{1}{4}$ of sensible heat lost by the ocean goes to ice melt. The rest is transferred to the atmosphere. The constant expression validates the assumption that $f$ is constant used in the derivation above. However, $\alpha$ varies strongly with temperature, and a different stratification with considerably warmer deep water would, while not changing (26), lead to a larger value for $f_{0}$. $f_{0}$ is twice the value required for marginal stability at the base of the mixed layer, i.e. $\Delta_{\mathrm{D}} \rho=0$ for $f=\frac{1}{2} f_{0}$ and when $f \leqslant \frac{1}{2} f_{0}$ no mixed layer can develop. The stratification would be unstable, and 
convection affects the entire water column. It may be noted that $\left(\frac{1}{2} f_{0}\right)^{-1}$, neglecting $\alpha \Delta T_{\mathrm{D}}$, is equal to the stability parameter $R$ introduced by Walin (1993). $f_{0}$ also implies that the contribution of melt water to the density step at the base of the mixed layer is twice as large and opposite to the temperature contribution. The total loss of sensible heat and the fractions going to the atmosphere and to ice melt are shown in Fig. 2 as functions of $f$.

When substituting Eq. (22) into Eq. (14) the flux of sensible heat at the sea surface becomes

$$
\frac{Q}{c \rho}=\frac{m_{0} u_{*}^{3}\left(\beta S_{\mathrm{D}}+\alpha \Delta_{\mathrm{D}} T\right)}{g \alpha\left(\beta S_{\mathrm{D}}-\alpha \Delta_{\mathrm{D}} T\right) H}+\frac{H}{2} \frac{\mathrm{d}\left(\Delta_{\mathrm{D}} T\right)}{\mathrm{d} t}
$$

and since $\beta S_{\mathrm{D}} \gg \alpha \Delta T$ this gives

$$
\frac{Q}{c \rho} \approx \frac{m_{0} u_{*}^{3}}{g \alpha H}+\frac{H}{2} \frac{\mathrm{d}\left(\Delta_{\mathrm{D}} T\right)}{\mathrm{d} t}
$$

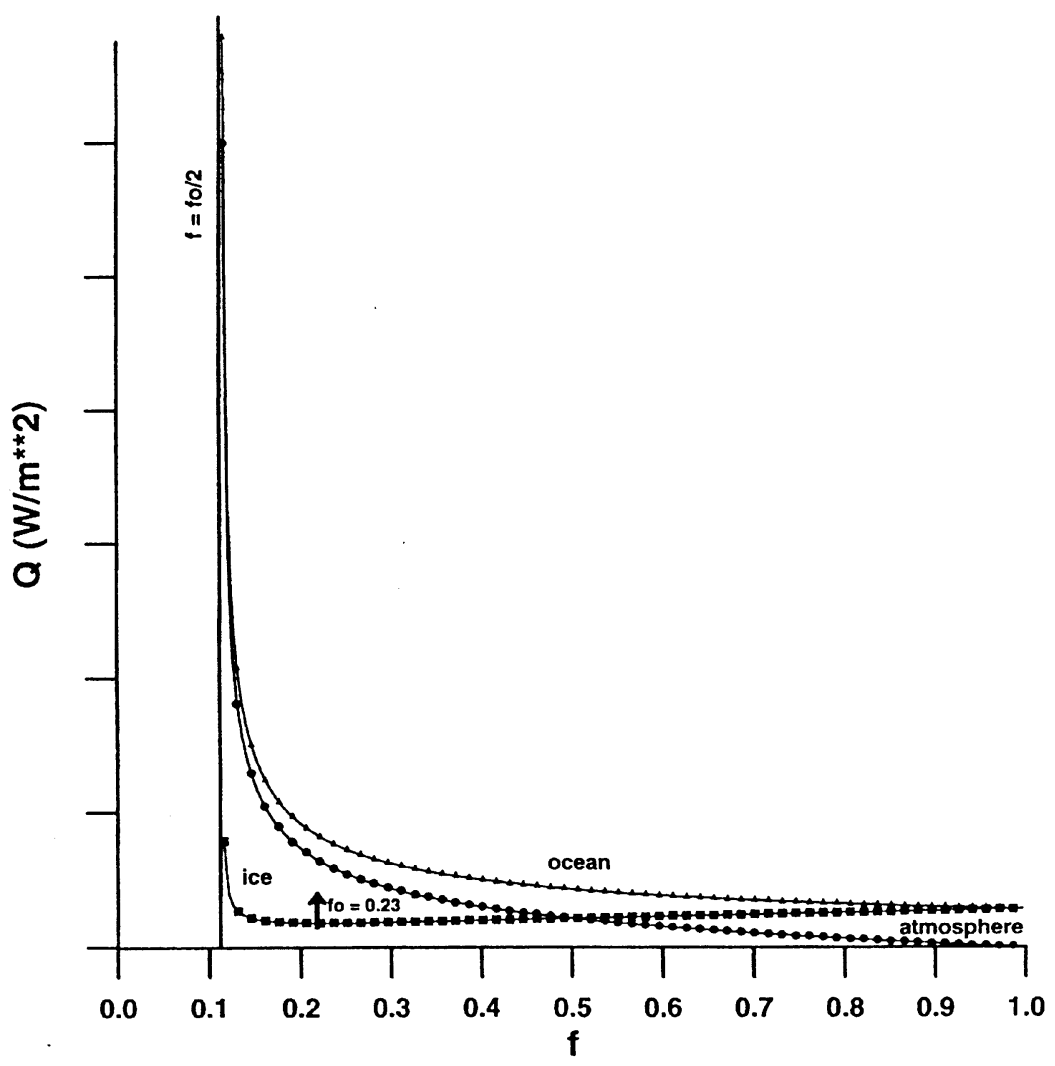

Fig. 2. The total flux of oceanic sensible heat, $Q$, the heat going to ice melt, $f Q$, and the atmosphere, $(1-f) Q$, as functions of $f$ for the case of a mixed layer formed out of ice melting on top of warmer water. The heat loss is arbitrary. The value $f_{0}$ giving minimum ice melt rate is indicated. For $f=\frac{1}{2} f_{0}$ the mixed layer is marginally stable. 
The first term on the right-hand side gives the entrained heat $Q_{\mathrm{e}}$, which then is independent of the stratification and only depends upon $H$. This determines a smallest possible depth $H_{0}$ for a mixed layer formed by the melting of sea ice. For depth less than $H_{0}$ the second term in Eq. (24) is negative, which requires that the upper layer becomes warmer. This is not possible because of heat loss and melting. The mixed layer therefore instantaneously attains the depth $H_{0}$, where the entrained heat, $Q_{\mathrm{e}}$, balances the heat loss to ice melt and the atmosphere. When the depth increases, the mixed layer must cool to supply the heat loss to the atmosphere and to ice melt, increasing the temperature step $\Delta_{\mathrm{D}} T$ (Fig. 1).

In the derivation of $f_{0}$ it was implicitly assumed that the atmosphere absorbs all heat lost by the ocean, and not going to ice melt. In reality this is not likely. The heat flux to the atmosphere is set by the temperature difference between the atmosphere and the sea and upper ice surfaces (see Section 3 below). We therefore expect $H_{0}$ to adjust in such a way that the heat flux to the atmosphere is balanced by entrainment. This means that $H_{0}$ must be different for different $f_{0}$. To briefly examine the consequences of this, we assume that another hypothetical fraction $f^{\prime}=r f_{0}$ goes to ice melt. Eq. (22) then takes the form

$$
f^{\prime}=r f_{0}=\frac{2 r \alpha L}{c\left(\beta S_{\mathrm{D}}-\alpha \Delta T\right)}
$$

which introduced into (15) gives the expression

$$
\frac{Q}{c \rho} \approx \frac{m_{0} u_{*}^{3}}{g \alpha(2 r-1) H}+\frac{H}{2} \frac{\mathrm{d}\left(\Delta_{\mathrm{D}} T\right)}{\mathrm{d} t}
$$

corresponding to Eq. (24). To supply same heat flux to the atmosphere with $f_{0}$ as with $f^{\prime}$ we must have

$$
\left(1-f^{\prime}\right) Q^{\prime}=\left(1-f_{0}\right) Q
$$

where $Q^{\prime}$ is the total heat flux in the primed system, The amount of heat going to ice melt is then

$$
f^{\prime} Q^{\prime}=r f_{0} \frac{\left(1-f_{0}\right)}{\left(1-r f_{0}\right)} Q
$$

The effects of ice melt on the stability and entrainment are not considered here and $f^{\prime}$ is, as expected, larger than $f_{0}$ for $r>1$ and smaller for $r<1$. However, the melt water has to be stirred into a mixed layer of depth $H^{\prime \prime}{ }_{0}$, where the heat loss to the atmosphere balances the entrained heat. The buoyancy flux multiplied by the depth gives the change in potential energy as the initial mixed layer is formed. Since the buoyancy flux due to ice melt is proportional to the heat going to ice melt, this change is proportional to

$$
f^{\prime} Q^{\prime} H^{\prime}{ }_{0}=r f_{0} \frac{\left(1-f_{0}\right) m u_{*}^{3} H^{\prime}{ }_{0}}{\left(1-r f_{0}\right) g \alpha(2 r-1) H^{\prime}{ }_{0}}
$$


where Eq. (24') and Eq. (26) have been used. The change of potential energy is a function of the ratio $r=f^{\prime} f_{0}^{-1}$, and it has a minimum for $r=\left(2 f_{0}\right)^{-1 / 2} \approx 1.47$. This corresponds to a value of 0.33 for the fraction $f^{\prime}$ going to ice melt. This is different from $f_{0}$. Nothing else is to be expected considering the different requirements for which $f^{\prime}$ and $f_{0}$ were derived. What is interesting is that the initial mixed layer depth may adjust in such a way that a minimum of the energy input, related to the stirring of melt water into the mixed layer, does exist. It is also encouraging that the fraction for which it occurs is not far from $f_{0}$, giving minimum ice melt, which was derived above and which we shall adopt for the rest of this work.

A second observation about $H_{0}$ is that it is not related to the Monin-Obukhov depth, which gives the maximum depth a mixed layer, subject to wind mixing and buoyancy input, can attain. $H_{0}$ is the minimum depth a homogeneous mixed layer with temperature above freezing and subject to cooling, melt water input and wind stirring may have. The different cases run in Section 4 show that, if its temperature is above freezing, the mixed layer will attain a stage with no deepening, which corresponds to the Monin-Obukhov depth.

\subsection{The evolution of the mixed layer in winter}

The high-latitude mixed layers have finite depth, are less saline than the underlying water, and are cooled to freezing temperature in autumn. If a mixed layer with depth $(H+\delta) \mathrm{m}$ is looked upon as $H \mathrm{~m}$ of water from the underlying ocean to which $\delta \mathrm{m}$ of freshwater have been added, salt conservation gives the relation between $S$ and $S_{\mathrm{D}}$ as

$$
(H+\delta) S=H S_{\mathrm{D}}
$$

It is the freshwater content that controls the stability at the base of the mixed layer. We therefore introduce the freshwater fraction $f_{\mathrm{w}}$, which relates $\delta$ to the sensible heat that is made available, if $H \mathrm{~m}$ of underlying water is cooled by $\Delta_{\mathrm{D}} T$ degrees to attain the mixed layer temperature. We then obtain

$$
f_{\mathrm{w}}=\frac{L \delta}{c \Delta_{\mathrm{D}} T H}
$$

and eliminating $\delta$ using Eq. (28) gives

$$
f_{\mathrm{w}}=\frac{L\left(S_{\mathrm{D}}-S\right)}{\left(c \Delta_{\mathrm{D}} T\right) S} .
$$

We shall use $f_{\mathrm{w}}$ instead of $S$ when describing the mixed layer evolution. $f_{\mathrm{w}}$ enters the expression for the buoyancy step below the mixed layer, Eq. (3), as

$$
g \Delta_{\mathrm{D}} \rho^{\prime}=g \alpha \Delta_{\mathrm{D}} T\left(\frac{f_{\mathrm{w}} c \beta S_{\mathrm{D}}}{\alpha L\left(1+\left(f_{\mathrm{w}} c / L\right) \Delta_{\mathrm{D}} T\right)}-1\right) .
$$

In a situation with no initial mixed layer as considered in Section 2.1, the $f$ entering the buoyancy flux (Eq. (9)), and the $f_{\mathrm{w}}$ entering $g \Delta \rho^{\prime}$ (Eq. (31)) are the same. This is so 
because ice melt and cooling alone control the stability at the base of the mixed layer. When an existing mixed layer is brought to freezing temperature and ice forms, negative buoyancy input due to brine release is present, and this coupling is broken. However, freezing does not exclude the possibility of melting, and the volumes of ice formed and melted may be substantially larger than the net ice formation. We shall require that the fraction of sensible heat going to ice melt, also in this situation, is given by the $f_{0}$. We assume that the mixed layer must be at freezing temperature for ice to form, and the expression for the entrainment velocity becomes

$$
\begin{gathered}
w_{\mathrm{e}}=\frac{m_{0} u_{*}^{3}\left(1+f_{\mathrm{w}} \frac{c}{L} \Delta_{\mathrm{D}} T\right)}{g \alpha \Delta_{\mathrm{D}} T\left(\left(f_{0}+f_{\mathrm{w}}\right) \frac{c \beta S_{\mathrm{D}}}{2 \alpha L}-\left(1+f_{\mathrm{w}} \frac{c}{L} \Delta_{\mathrm{D}} T\right)\right) H} . \\
+\frac{0.025\left(Q_{\mathrm{a}}\left(1-f_{0}\right) Q_{\mathrm{e}}\right) \frac{g \beta S_{\mathrm{D}}}{\rho L}}{g \alpha \Delta_{\mathrm{D}} T\left(\left(f_{0}+f_{\mathrm{w}}\right) \frac{c \beta S_{\mathrm{D}}}{2 \alpha L}-\left(1+f_{\mathrm{w}} \frac{c}{L} \Delta_{\mathrm{D}} T\right)\right)} .
\end{gathered}
$$

When $T=T_{f}$ the cooling term disappears and the loss of sensible heat by the ocean, $Q$, is equal to $Q_{\mathrm{e}}$, and the heat flux $Q_{\mathrm{a}}$ to the atmosphere now also includes latent heat released by freezing. The positive buoyancy term due to ice melt has, as in Section 2.1, been incorporated into the mechanical stirring term. The second term comes from the negative buoyancy input due to the ice formation needed to close the heat balance with the atmosphere. The appropriate values for $\varepsilon(1$ and 0.05$)$ for the two processes have been introduced. The dynamic effect of freezing and brine release is kept separate from the buoyancy input from melting. Freezing is unequivocally distinct from melting, and the released brine has high enough density excess to convect in spite of neighbouring areas with melting ice. It then contributes to the stirring of the mixed layer and to entrainment of water from below.

\subsection{Convection, ice melt and restratification}

By freezing (and also by cooling, when no ice is present) small density anomalies, positive as compared to the mixed layer, continuously form at the sea surface and convect. The density difference between the mixed layer and the deep ocean disappears when $f_{\mathrm{w}}=\frac{1}{2} f_{0} H . w_{\mathrm{e}}$ are still finite, and the convecting parcels will sink into the deep ocean. The mixed layer is then removed and the underlying ocean rises toward the sea surface and the ice, and a melting situation as the one discussed in Section 2.1 would follow. Convection and restratification take place simultaneously. We assume that convection only occurs in a small part of the area, but the convection velocity is much larger than the entrainment velocity and the old, dense mixed layer is removed. A new mixed layer then forms out of the by-passed, rising part of the underlying water column (Fig. 3). Since it is created by melting, the results from 2.1 apply. A new 

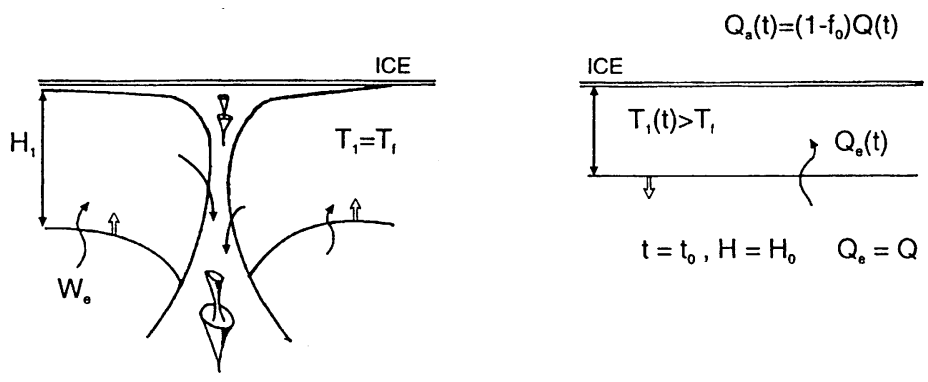

time

Fig. 3. The breakthrough of the convection out of the mixed layer and the reformed mixed layer after $t=t_{0}$ when the entrained heat balances the heat loss to the atmosphere.

mixed layer is considered established when it has attained the depth, $H_{0}$, where the entrained heat balances the heat loss to the atmosphere (Fig. 3). From Eq. (24) we get

$$
H_{0}=\frac{\left(1-f_{0}\right) m_{0} u_{*}^{3} \rho c}{g \alpha Q_{\mathrm{a}}} .
$$

In the situation considered in Section 2.1 no convection and removal of an old mixed layer take place, and this depth was attained immediately. Here a phase exists when water from below is entrained into the receding mixed layer. Not having a convection model to tell us the time needed for the mixed layer to convect, we instead estimate the time needed for a volume, corresponding to $H_{0}$, to become entrained across the lower boundary. The entrainment velocity changes during this phase because of the changing depth of the mixed layer. The mean entrainment velocity is therefore, ad hoc, approximated by $w_{\mathrm{e}} H\left(H_{0}\right)^{-1}$, where $w_{\mathrm{e}}$ is the entrainment velocity and $H$ the depth of the mixed layer immediately before the convection; the ratio $H\left(H_{0}\right)^{-1}$ is introduced to take into account the increase in entrainment velocity as the depth of the mixed layer decreases because of the convection. The time $t_{0}$ needed for the mixed layer to reform then becomes

$$
t_{0}=H_{0}^{2} / w_{\mathrm{e}} H \text {. }
$$

Heat is supplied to the atmosphere during this restratification phase, and once $t_{0}$ is determined, the temperature step $\Delta_{\mathrm{D}} T$ at the base of the newly formed mixed layer is estimated from

$$
\Delta_{\mathrm{D}} T=\frac{Q_{\mathrm{a}} t_{0}}{\left(1-f_{0}\right) \rho c H_{0}} .
$$

As will be noticed below, the adopted expression for $t_{0}$ makes $\Delta_{\mathrm{D}} T$ about half the previous temperature step, and after the convection a mixed layer with temperature above freezing is formed. The salinity of the new mixed layer is close to that just before 
the convection, and the stable density step due to salinity is twice the unstable density step due to temperature. This happens because restratification occurs so quickly that the atmosphere cannot absorb all sensible heat in the reformed mixed layer. The ice melt is limited, since it is coupled to the heat going to the atmosphere, not to a requirement that the mixed layer shall remain at freezing temperature. The ice melt during the restratification phase leads to reduction of the ice cover, and when the mixed layer is established, the heat loss to the atmosphere will be larger than the $Q_{\mathrm{a}}$ used to determine $H_{0}$.

As the mixed layer deepens, entrainment alone cannot supply enough heat to balance the heat loss to the atmosphere, which also increases because of melting, leading to thinner ice and larger fraction of open water. The heat stored in the mixed layer is used and $\Delta_{\mathrm{D}} T$ increases as

$$
\frac{\mathrm{d}\left(\Delta_{\mathrm{D}} T\right)}{\mathrm{d} t}=\frac{Q_{\mathrm{a}}-\left(1-f_{0}\right) Q_{\mathrm{e}}}{\left(1-f_{0}\right) H} .
$$

All fresh water comes from ice melt and $f_{\mathrm{w}}=f_{0}$ and the entrainment velocity is given by

$$
w_{\mathrm{e}}=\frac{m_{0} u_{*}^{3}\left(1+f_{\mathrm{w}} \frac{c}{L} \Delta_{\mathrm{D}} T\right)}{g \alpha \Delta_{\mathrm{D}} T\left(\left(f_{0}+f_{\mathrm{w}}\right) \frac{c \beta S_{\mathrm{D}}}{2 \alpha L}-\left(1+f_{\mathrm{w}} \frac{c}{L} \Delta_{\mathrm{D}} T\right)\right) H}-\frac{H}{2 \Delta_{\mathrm{D}} T} \frac{\mathrm{d}\left(\Delta_{\mathrm{D}} T\right)}{\mathrm{d} t} .
$$

If the temperature again falls to the freezing point, ice begins to form, and $w_{\mathrm{e}}$ is again given by Eq. (32). The density step starts to decrease and is eventually removed and a new deep convection event occurs. Should the ice cover disappear before freezing temperature is reached, continued cooling makes the mixed layer unstable before ice can form, or only a brief spell of freezing occurs before the layer convects. The ice then melts, and if the stability of the underlying ocean is weak, no further ice formation takes place. The rest of the winter will be dominated by thermal convection.

\section{Heat loss to the atmosphere and evolution of the ice cover}

So far it has not been necessary to consider explicitly the atmospheric forcing and the evolution of the ice cover. However, to study concrete situations some parameterisation of these processes must be introduced. We mainly follow Washington and Parkinson (1986), and for a more thorough treatment of sea ice mechanics and thermodynamics we refer to this work and to Hibler (1979), Hibler and Flato (1992) and the books edited by Untersteiner (1986) and Smith (1990).

The heat flux to the atmosphere is approximated by a Newtonian transfer law (Washington and Parkinson, 1986):

$$
\begin{aligned}
& Q_{0}=K U_{\mathrm{a}}\left(T_{\mathrm{a}}-T_{0}\right)+L_{\mathrm{e}} \\
& Q_{\mathrm{i}}=K U_{\mathrm{a}}\left(T_{\mathrm{a}}-T_{\mathrm{s}}\right)
\end{aligned}
$$


$Q_{0}$ specifies the surface heat flux for open water, with $L_{\mathrm{e}}$ being the latent heat loss, $Q_{\mathrm{i}}$ is the heat flux over ice, and $U_{\mathrm{a}}$ is the wind speed. It is assumed that the main effects of the long wave radiation can be parameterised by a larger $T_{\mathrm{a}}$, and $T_{\mathrm{a}}$ is an "effective" air temperature. Only the winter season is considered, and incoming short wave radiation is neglected. $T_{0}$ and $T_{\mathrm{s}}$ are surface temperatures for ocean and ice, respectively. The value of the transfer coefficient $K$ is kept constant. To quantify $L_{\mathrm{e}}$ we assume a constant difference of 0.002 between the specific humidity of the air, $q_{\mathrm{a}}$, and its corresponding saturation value, $q_{\mathrm{w}} . L_{\mathrm{e}}$ is then obtained from

$$
L_{\mathrm{e}}=K U_{\mathrm{a}}\left(q_{\mathrm{a}}-q_{\mathrm{w}}\right) L_{\mathrm{v}} / c_{\mathrm{p}},
$$

where $L_{\mathrm{v}}=2.5 \times 10^{6} \mathrm{~J} \mathrm{~kg}^{-1}$ gives the value for latent heat of vaporisation. The friction velocity $u_{*}$ is related to the wind velocity by the friction law

$$
u_{*}^{3}=\frac{\rho_{\mathrm{a}}}{\rho} C_{\mathrm{D}} U_{\mathrm{a}}^{2} .
$$

The growth of the ice cover has two components: lateral and vertical. The lateral growth reduces the area of open water. The vertical growth increases the ice thickness. Following Parkinson and Washington (1979) we simulate the growth in both components by hypothesising that when freezing starts, the ice formed in the open water is accumulated onto, initially infinitesimally narrow, ice floes of initial thickness $d_{0}$. These floes then grow vertically by heat conduction and freezing at their lower boundary and horizontally by a continuous, equally distributed, accumulation at the sides of the floes, of ice formed in open water. The existence of motions to support such a pattern, like ice convergences created by wind or currents, is assumed. In melting phases the ice thickness $d$ is not allowed to become smaller than $d_{0}$. As an initial value $d_{0}=0.1 \mathrm{~m}$ is used.

The heat budget for open water involves two sources, entrainment and freezing, to balance the loss to the atmosphere. The total ice volume produced in open water is given by $I$, and the volume production rate is

$$
\dot{I}=\frac{\left(Q_{0}-Q_{\mathrm{e}}\right) A}{\rho_{\mathrm{i}} L} .
$$

We assume that the mixed layer must to be at the freezing point for ice to form. This means that Eq. (40) only holds when $Q=Q_{\mathrm{e}}$. Also in this case $f_{0} Q_{\mathrm{e}}$ of the oceanic sensible heat loss goes to ice melt, but when the mixed layer water is at freezing temperature, it is not necessary to separate melting and freezing in the ice balance. The accumulation of ice at the edge of the existing ice floes changes $A$, the fraction of open water, according to

$$
\dot{A}=\frac{\left(Q_{0}-Q_{\mathrm{e}}\right) A}{\rho_{\mathrm{i}} L d} .
$$

We only study seasonal ice covers formed in the Greenland Sea and the Weddell Sea, and their thickness will be limited to about $0.5 \mathrm{~m}$. We therefore do not consider it necessary to apply a complex multi-layer ice model, including snow cover, and we 
assume that the ice can be approximated by a homogeneous, conducting slab. The heat loss through the ice is then given by

$$
Q_{\mathrm{i}}=\kappa_{\mathrm{i}}\left(T_{\mathrm{s}}-T_{\mathrm{f}}\right) / d
$$

where the lower ice boundary is assumed to be at freezing temperature. The heat transfer between water and ice is not explicitly modelled. When $T>T_{\mathrm{f}}$ entrainment and cooling of the mixed layer supply all heat both to ice melt and to the atmosphere. For $T=T_{\mathrm{f}}$ entrained heat goes both to ice melt, and is conducted through the ice. Freezing at the bottom then closes the balance with $Q_{\mathrm{i}}$. By substituting $Q_{\mathrm{i}}$ from (39) the ice surface temperature is eliminated (Hibler and Flato, 1992);

$$
Q_{\mathrm{i}}=\frac{\kappa_{\mathrm{i}} K U_{\mathrm{a}}}{\kappa_{\mathrm{i}}+K U_{\mathrm{a}} \mathrm{d}}\left(T_{\mathrm{a}}-T_{\mathrm{f}}\right)
$$

The coefficient of heat conduction in ice, $\kappa_{\mathrm{i}}=2.0 \mathrm{~J}^{\circ} \mathrm{C}^{-1} \mathrm{~m}^{-1} \mathrm{~s}^{-1}$, and the coefficient of heat transfer, $K=1.43 \mathrm{~J}^{\circ} \mathrm{C}^{-1} \mathrm{~m}^{-3}$, keep their adopted values throughout. If the storage of sensible heat in the ice is neglected, the vertical growth of the ice is given by

$$
\dot{d}=\left(Q_{\mathrm{i}}-Q\right) / \rho_{\mathrm{i}} L .
$$

For simplicity the salinity of sea ice is again set to zero. The salt content of sea ice is due to trapping of sea water between ice crystals in the freezing process. This water will increase the thickness of the ice. The overestimate of the heat conduction through the ice cover caused by underestimating its thickness is not expected to be serious.

In melting phases the heat loss to the atmosphere is given by

$$
Q_{\mathrm{a}}=A Q_{0}+(1-A) Q_{\mathrm{i}}=\left(1-f_{0}\right) Q
$$

where the right-hand side gives the loss of sensible heat by the ocean to the atmosphere. The temperature at the lower boundary of the ice is kept at the freezing point and $Q_{\mathrm{i}}$ is still given by (45). We use this combined equation because when $T$ is above freezing no new ice forms in open water and it is not be possible to separately balance the heat loss through the ice and the heat loss in the open areas. The change in ice volume $v$ becomes

$$
\dot{v}=f_{0} Q / \rho_{\mathrm{i}} L
$$

We approximate the fraction of open water by an exponential function:

$$
A=\exp \{-\lambda v\}
$$

where the scale factor

$$
\lambda=\frac{\ln A_{\mathrm{m}}}{v_{\mathrm{m}}}
$$

is set from $A_{\mathrm{m}}$, the area of open water, and $v_{\mathrm{m}}$, the ice volume, just before the convection. The thickness of the ice then evolves as

$$
\dot{d}=v /(1-A) .
$$


This is prescribed to hold until the ice thickness is reduced to $d_{0}$. After that the ice is considered to be predominantly collected into ice bands of thickness $d_{0}$. The expressions for the changes in ice volume and area of open water are then given by

$$
\dot{v}=\mathrm{d}_{o} \frac{\mathrm{d}(1-A)}{\mathrm{d} t}=-\frac{f_{0} Q}{\rho_{\mathrm{i}} L} \Rightarrow \dot{A}=\frac{f_{0} Q}{\mathrm{~d}_{0} \rho_{\mathrm{i}} L} .
$$

\section{Numerical examples}

The present integral approach describes the evolution of bulk parameters such as mixed layer salinity and depth, the heat fluxes, the entrainment velocity and the average ice thickness and the ice surface temperature. It should then answer the question: Is deep penetrating haline convection in the ocean possible, at least to the extent that the present formulation of the problem is valid?

The model is one-dimensional and has two layers, a mixed layer above a deep homogeneous ocean. Computations are made with 1-hour time steps. The mixed layer is initially at the freezing point and $w_{\mathrm{e}}$ is determined using Eq. (31), which multiplied by the temperature step gives the heat flux from the lower layer. The heat transfer to the atmosphere at open water and through ice is given by Eqs. (38) and (39). The heat conduction through the ice is then found from Eq. (45) with an initial ice thickness $d_{0}$. The increase in ice thickness during one time step is obtained from the difference between entrained heat and heat conduction. The thickness multiplied by the fraction of ice covered water then gives the ice volume formed under ice. The change in the area of open water is taken from Eq. (42), where the ice thickness from the previous time step is used. The ice growth in open water is then computed by the change in area of open water times the ice thickness.

Entrainment and ice formation change the depth of the mixed layer as

$$
\frac{\mathrm{d} H}{\mathrm{~d} t}=w_{\mathrm{e}}-\frac{\rho_{\mathrm{i}}}{\rho_{\mathrm{w}}}(\dot{I}+(1-A) \dot{d})
$$

and its salinity by

$$
\frac{\mathrm{d}(H S)}{\mathrm{d} t}=w_{\mathrm{e}} S_{\mathrm{D}}
$$

If the stability $\left(\beta \Delta_{\mathrm{D}} S-\alpha \Delta_{\mathrm{D}} T\right)$ at the base of the mixed layer becomes zero, the mixed layer convects. The equilibrium depth of the new mixed layer and the time needed for it to be established are estimated from (33) and (34). The new $\Delta_{\mathrm{D}} T$ is determined from (35) and, because the new mixed layer is formed from melting ice, $f_{\mathrm{w}}=f_{0}$. For $T>T_{\mathrm{f}}$ the entrainment velocity is computed using (37). The heat loss and the reduction of the ice cover are calculated using (47)-(49). $H$ and $S$ are again found using (53) and (54) and the temperature change is determined from

$$
\frac{\mathrm{d} T}{\mathrm{~d} t}=\frac{Q_{\mathrm{a}}-Q}{H} .
$$


If $d$ becomes equal to $d_{0}$ the ice thickness stays constant and the area of open water changes as (52). If $T$ reaches the freezing point before all ice is melted, ice starts to form and the initial expressions are adopted. A second instability arises, deep convection follows and again a mixed layer is reformed. The calculations were continued until the ice cover had disappeared. In cases with high initial stability and no convection the computations were terminated after 208 days.

\subsection{The relative effects of wind speed, air- and deep water temperature}

A mixed layer initially at freezing temperature, with salinity $S=34.65$ and a depth of $80 \mathrm{~m}$ lies above a deep layer with $T_{\mathrm{D}}=-0.9^{\circ} \mathrm{C}$ and $S_{\mathrm{D}}=34.85$. The atmospheric forcing is given by $U_{\mathrm{a}}=5$ or $10 \mathrm{~m} \mathrm{~s}^{-1}$ and $T_{\mathrm{a}}=-20$ or $-30^{\circ} \mathrm{C}$. The time evolution of different parameters are shown in Fig. 4 for $U_{\mathrm{a}}=5$ and $10 \mathrm{~m} \mathrm{~s}^{-1}$ and $T_{\mathrm{a}}=-30^{\circ} \mathrm{C}$. The first panel displays the variations of the heat flux to the atmosphere, $Q_{\mathrm{a}}$, and the heat entrained from below, $Q_{\mathrm{e}}$. The second panel shows the atmosphere and ice surface temperatures $T_{\mathrm{a}}$ and $T_{\mathrm{s}}$. The third panel indicates the changes in ice thickness $d$, and fraction of open water $A$. Panel 4 gives the mixed layer depth $H$, panel 5 the temperature in the mixed layer and the underlying ocean $T$, $T_{\mathrm{D}}$ and panel 6 the corresponding salinities $S, S_{\mathrm{D}}$. The initial conditions are given in Table 1 and the results are summarised in Table 2.

The greatest difference arises from changes in wind speed. When the wind is strong, $Q_{\mathrm{a}}$ and $Q_{\mathrm{e}}$ almost balance (Fig. 4a, first panel). The ice initially grows rapidly and thin ice covers the entire sea surface (3rd panel). There is a weak increase in the heat transfer from below (1st panel), and the ice thickness has a maximum and then begins to melt slightly (3rd panel). The mixed-layer depth increases rapidly as shown in panel 4. After the initial net ice growth, because of the established balance between ice formation and ice melt, the salinity increase is due to entrainment from below (6th panel). The entrained water loses its heat but adds salt to the mixed layer. The density of the mixed layer increases until the stability is gone. The mixed layer then convects. In the case with lower temperature just enough ice is formed to create a new mixed layer of depth $H_{0}$ after the convection. (The gaps in the diagrams indicate the unresolved periods of convection and restratification before the formation of a mixed layer with depth $H_{0}$.) Less than 3 days after the new mixed layer is established, the ice has melted. With the higher air temperature the ice thickness is always less than the initially prescribed $d_{0}=0.1 \mathrm{~m}$ and not enough ice is formed to create a mixed layer of thickness $H_{0}$ after the convection (Table 2).

With a lower wind speed the picture is different (Fig. 4b). No balance is reached between $Q_{\mathrm{a}}$ and $Q_{\mathrm{e}}$ before the stability is gone and the mixed layer convects (1st panel). A small fraction of open water is present and the ice thickness is still increasing, when the stability is gone ( $3 \mathrm{rd}$ panel). After the convection a mixed layer with temperature above freezing is created. As the mixed layer deepens, its temperature and salinity is reduced, but $f_{\mathrm{w}}$ stays constant. The larger layer depth and stability reduce the entrainment velocity, and it becomes zero. The mixed layer has now attained the Monin-Obukhov depth, which is about twice as deep as $H_{0}$ (4th panel). A cooling, but no deepening, of the mixed layer then follows until the mixed layer temperature 

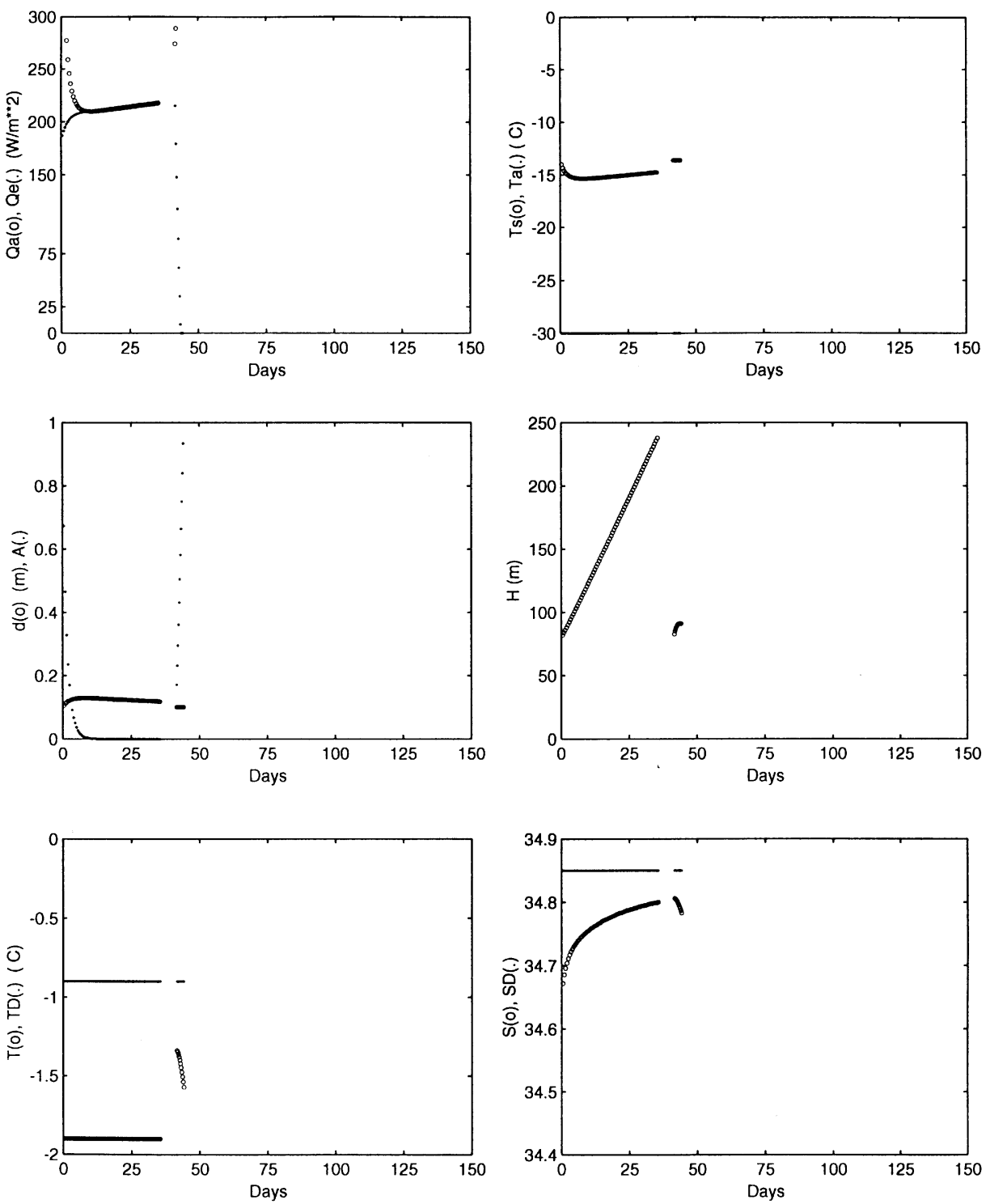

(a)

Fig. 4. The evolution of the mixed layer. Panel 1 shows the heat loss to atmosphere, $Q_{\mathrm{a}}$, and the entrained heat, $Q_{\mathrm{e}}\left(\mathrm{W} \mathrm{m}{ }^{-2}\right)$; Panel 2 the atmosphere and the ice surface temperature, $T_{\mathrm{a}}$ and $T_{\mathrm{s}}\left({ }^{\circ} \mathrm{C}\right)$; Panel 3 the ice thickness, $d(\mathrm{~m})$ and the fraction of open water, $A$. Panel 4 gives the mixed layer thickness, $H(\mathrm{~m})$; Panel 5 shows the mixed layer temperature, $T$ and the deep water temperature $T_{\mathrm{D}}\left({ }^{\circ} \mathrm{C}\right)$ and panel 6 the corresponding salinities $S$ and $S_{\mathrm{D}}$. The values are given for every 12 hour before the first convection and then after every 6 hour. The gaps indicate the unresolved convection and restratification periods $t_{0}$. The stability across the base of the mixed layer is the same for the two cases and the temperature and salinity of the lower layer are $-0.9^{\circ} \mathrm{C}$ and 34.85 . Air temperature is $-30^{\circ} \mathrm{C}$. (a) $U_{\mathrm{a}}=10 \mathrm{~m} \mathrm{~s}^{-1}$, (b) $U_{\mathrm{a}}=5 \mathrm{~m} \mathrm{~s}^{-1}$. 

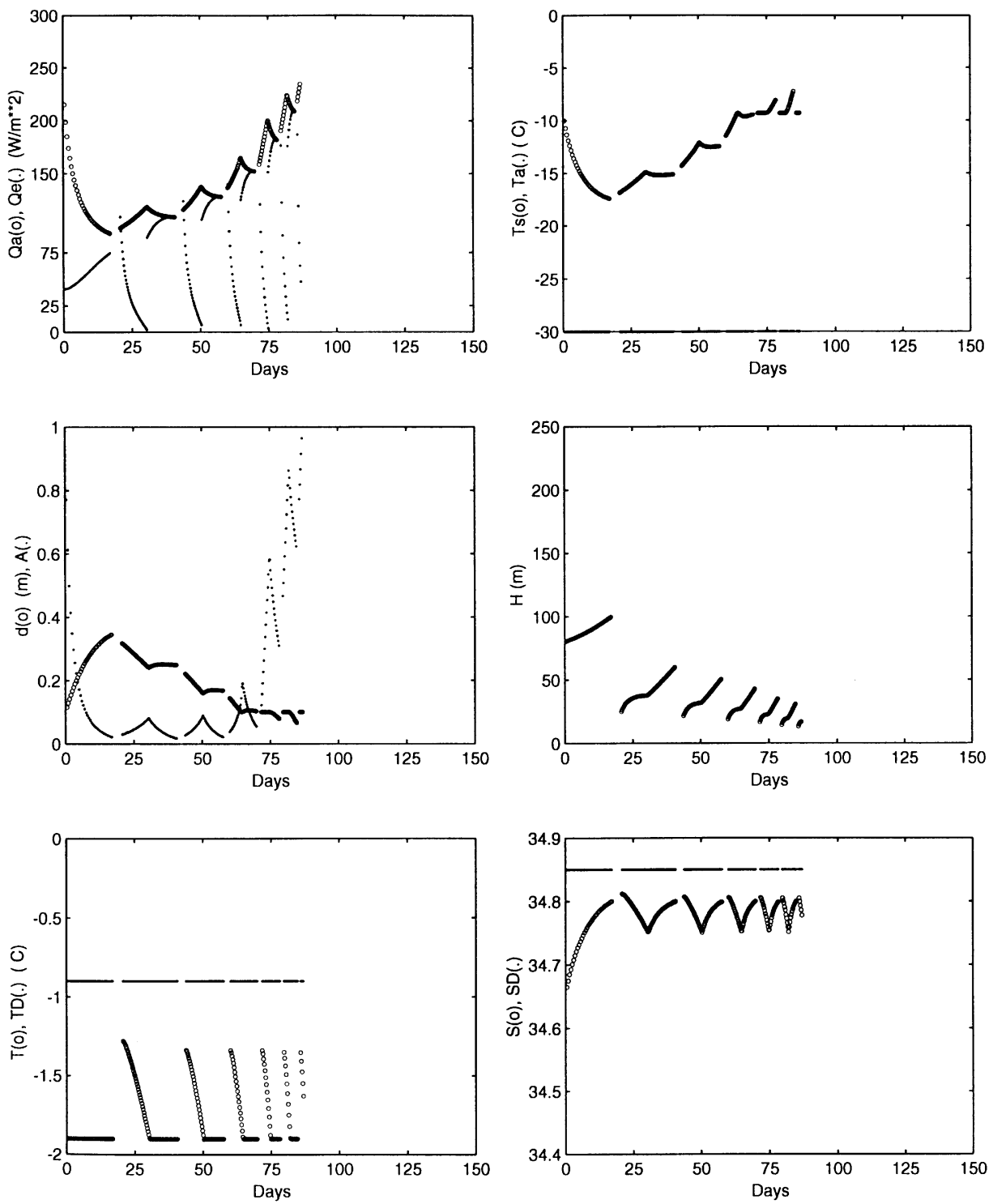

(b)

Fig. 4. Continued.

reaches the freezing point and ice begins to form (3rd and 5th panels). The stabilising effect of net melting then disappears, and the mixed layer again deepens. The heat loss to the atmosphere is reduced because of increased ice thickness and smaller A (3rd panel). The decrease in stability caused by freezing allows the entrainment from below to become large enough to balance the heat loss to the atmosphere (1st panel). 
Table 1

Initial conditions for the 6 test cases

\begin{tabular}{llllllll}
\hline exp. & $T_{1}\left({ }^{\circ} \mathrm{C}\right)$ & $S_{1}$ & $T_{2}\left({ }^{\circ} \mathrm{C}\right)$ & $S_{2}$ & $H_{1}(\mathrm{~m})$ & $T_{\mathrm{a}}\left({ }^{\circ} \mathrm{C}\right)$ & $U_{\mathrm{a}}\left(\mathrm{ms}^{-1}\right)$ \\
\hline 1 & -1.9 & 34.65 & -0.9 & 34.85 & 80 & -30 & 10 \\
2 & -1.9 & 34.65 & -0.9 & 34.85 & 80 & -20 & 10 \\
3 & -1.9 & 34.65 & -0.9 & 34.85 & 80 & -30 & 5 \\
4 & -1.9 & 34.65 & -0.9 & 34.85 & 80 & -20 & 5 \\
5 & -1.9 & 34.65 & -0.5 & 34.87 & 80 & -25 & 7 \\
6 & -1.9 & 34.65 & -1.3 & 34.83 & 80 & -25 & 7 \\
\hline
\end{tabular}

No net ice formation then occurs. The salinity continues to increase because of entrainment, and $f_{\mathrm{w}}$ drops toward $\frac{1}{2} f_{0}$. The mixed layer again becomes unstable and convects. After the convection the mixed layer is shallower than the initially prescribed $80 \mathrm{~m}$, but it more than doubles its thickness before the next convection event occurs. For $T_{\mathrm{a}}=-20^{\circ} \mathrm{C}$ the mixed layer is reformed 4 times after which the ice disappears. When $T_{\mathrm{a}}=-30^{\circ} \mathrm{C}$ enough ice has formed for 6 deep convection events to occur. The time intervals between the convection events decrease because freshwater is exported by convection into the deep ocean and the ice thickness is reduced, causing a larger heat loss to the atmosphere. However, the fraction of open water does not rise above 0.2 until at the very close to the disappearance of the ice (3rd panel).

The effects of the temperature difference between the mixed layer and the underlying water are studied in cases 5 and 6 (Table 1 and 2). The same forcing $\left(U_{\mathrm{a}}=7 \mathrm{~m}\right.$ $\mathrm{s}^{-1}$ and $T_{\mathrm{a}}=-25^{\circ} \mathrm{C}$ ) is applied to a mixed layer situated above deep layers with temperature $T_{\mathrm{D}}=-0.5^{\circ} \mathrm{C}$ and $T_{\mathrm{D}}=-1.3^{\circ} \mathrm{C}$ respectively. The initial mixed layer depth is $80 \mathrm{~m}$ both cases. A higher temperature in the underlying water leads to larger $Q_{\mathrm{e}}$ and thinner ice cover. In both cases a balance between $Q_{\mathrm{a}}$ and $Q_{\mathrm{e}}$ is reached before the water column becomes unstable. The convection starts earlier for the colder water column, while the ice disappears first for the warmer deep layer. Case 6 with larger ice volume and lower deep water temperature requires three convection events before the ice cover has melted. For the warmer second layer (case 5) only one deep convection occurs (Table 2).

From these idealised situations it appears that cold air, weaker winds and cold underlying water are the conditions most favourable for generating instability and deep convection events. Strong winds and perhaps also higher temperatures in the second layer promote a larger heat loss from the ocean and a more rapid removal of the ice. In a model formulated like the present one, deep convection has to occur at least once, before the ice can be removed by melting.

Several cases also were run with the same forcing as 5 and 6 but with different $f$ (Table 3). The convection starts earlier for larger $f$. The larger fraction of heat used to melt ice increases the stability at the base of the mixed layer, and less heat is entrained. This leads to stronger ice formation. More brine is released into a shallower layer, and the water column becomes unstable more rapidly in spite of a thicker ice cover. For small $f$ the stability at the base of the mixed layer is weaker and entrainment 


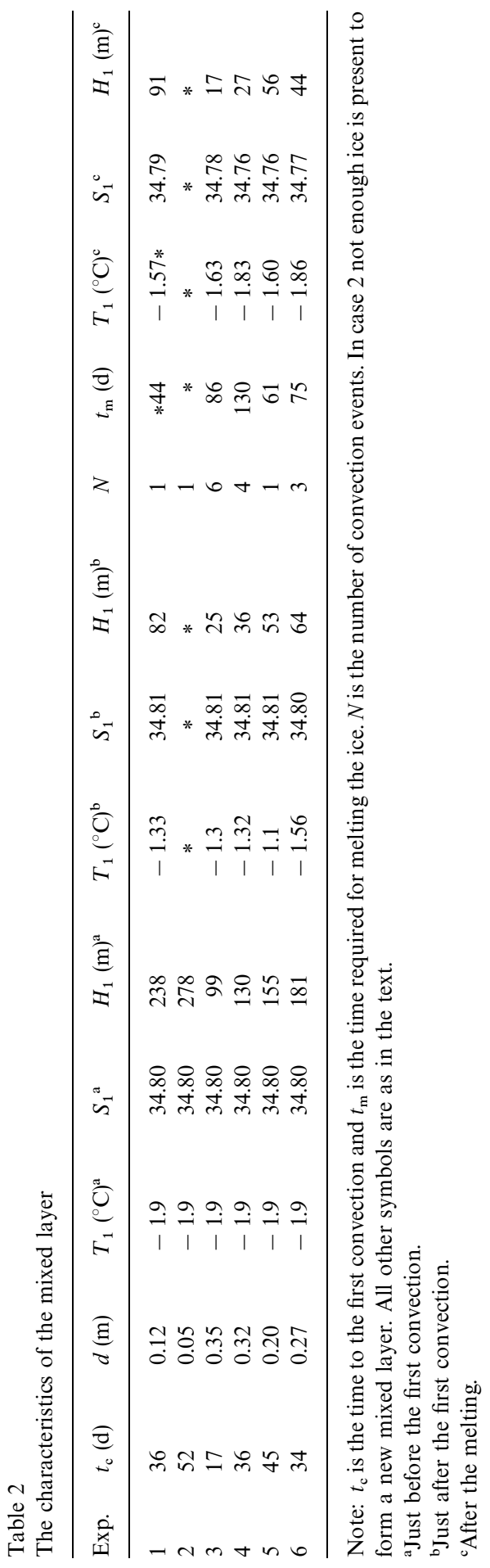


Table 3

Experiments 5 and 6 with different values of $f$

\begin{tabular}{llllllll}
\hline Exp & $f$ & $E B$ & $t_{\mathrm{c}}(\mathrm{d})$ & $d(\mathrm{~m})$ & $H(\mathrm{~m})$ & $N$ & $t_{\mathrm{m}}(\mathrm{d})$ \\
\hline 5 & 0.80 & - & 13 & 0.36 & 87 & 1 & 13 \\
5 & 0.50 & - & 17 & 0.34 & 94 & 1 & 17 \\
5 & 0.25 & - & 40 & 0.23 & 142 & 1 & 58 \\
5 & 0.23 & + & 45 & 0.20 & 155 & 1 & 61 \\
5 & 0.21 & + & 50 & 0,17 & 170 & 1 & 63 \\
5 & 0.19 & + & 53 & 0.12 & 190 & 1 & 67 \\
5 & 0.16 & + & 66 & 0.03 & 233 & 1 & 80 \\
6 & 0.80 & - & 13 & 0.36 & 93 & 2 & 17 \\
6 & 0.50 & - & 15 & 0.35 & 104 & 2 & 27 \\
6 & 0.25 & - & 29 & 0.29 & 162 & 4 & 76 \\
6 & 0.23 & + & 34 & 0.27 & 181 & 3 & 78 \\
6 & 0.21 & + & 39 & 0.25 & 207 & 2 & 82 \\
6 & 0.19 & + & 46 & 0.22 & 242 & 2 & 78 \\
6 & 0.16 & + & 60 & 0.14 & 327 & 1 & 73 \\
\hline
\end{tabular}

Note: EB indicates the energy balance of the mixed layer just before the first convection. + means that the entrained heat is larger than the heat loss to the atmosphere. $d$ and $H_{1}$ are the ice thickness and the mixed layer depth at the time of the first convection.

eventually supplies more heat than the atmosphere requires and net ice melt starts. The mixed layer then reaches large depths and needs more time before it becomes unstable and convects. Convection occurs for all cases with constant $f$, and the ice starts to melt. When $f$ is large the ice has melted before a mixed layer of depth $H_{0}$ has formed. For $f$ around 0.25 several convection events occur before the ice is removed. $Q_{\mathrm{e}}$ becomes slightly larger than $Q_{\mathrm{a}}$ for $f=0.23$ (our adopted value), but an approximate balance between heat loss to the atmosphere and entrained heat is reached and no net ice melt or freezing occurs when $f=f_{0}$. For $f$ less than 0.20 only little ice is formed and after the convection the ice quickly disappears.

\subsection{The Weddell Sea}

The importance of the Weddell Sea as a source of deep water for the world ocean is well known. Most of the dense-water formation occurs close to the Antarctic continent, on the shelves, and under the floating ice shelves (Gill, 1973; Killworth, 1983). However, Gordon observed a cold, narrow and almost homogeneous $4000 \mathrm{~m}$ deepwater column close to Maud Rise in the central Weddell Sea gyre, which he interpreted as remnants of deep-reaching open-ocean convection (Gordon, 1978). This convective feature or "chimney" was believed related to recurrent polynyas observed from satellites in late winter during the mid-70s (Zwally et al., 1983). This discovery led to intensive observational and modelling work to describe deep convection and conditions necessary for polynya formation (Killworth, 1979; Martinson et al., 1981; Martinson, 1990; Gordon and Huber, 1990; Lemke et al., 1991). We shall examine conditions representative of the Weddell Sea. Two background stratifications are 
considered: one based on observations in the "warm" regime and the other using observations at Maud Rise (Gordon and Huber, 1990). In the warm regime the underlying water has a temperature of $1.3^{\circ} \mathrm{C}$ and a salinity of 34.7. The salinity of the upper layer in autumn is estimated to be 34.11 (Gordon and Huber, 1990). Four situations with mixed-layer depths 20,40,60, and $80 \mathrm{~m}$ are considered. Air temperatures of $-20^{\circ} \mathrm{C}$ and wind velocities of $5 \mathrm{~m} \mathrm{~s}^{-1}$ are assumed. Two additional cases, one with an initial salinity of 34.21 , the other with an air temperature of $-25^{\circ} \mathrm{C}$ are also discussed. In these two cases the mixed-layer depth is set to $80 \mathrm{~m}$. The results are summarised in Table 4, and the evolution of the initially $80 \mathrm{~m}$ deep mixed layer for the standard forcing is shown in Fig. 5. Table 4 also gives mixed-layer depths, entrained heat and ice thickness as reported by Gordon and Huber (1990).

For initial depths of 20 and $40 \mathrm{~m}$ the density difference between the mixed layer and the underlying water column disappears. The mixed layer convects and the ice melts. For the thinnest layer not enough ice was formed to reform a mixed layer with depth $H_{0}$. The $40 \mathrm{~m}$ thick layer convected after 137 days and the ice was gone after 175 days, a month later than the end of the estimated winter period of 150 days (Gordon and Huber, 1990). Such mixed-layer depths are, however, considerably shallower than those observed in the area. In the other cases the water column remained stable throughout the winter. The heat loss to the atmosphere and the entrained heat were almost in balance by the end of the winter, and the heat loss at the sea surface was reduced from 165 to $40-50 \mathrm{~W} \mathrm{~m}^{-2}$. The mixed-layer deepening ranged between 25 and $35 \mathrm{~m}$, and the ice thickness was between 45 and $75 \mathrm{~cm}$. The salinity of the mixed layer after the winter was between 34.49 and 34.52. These values are all in the range of those reported by Gordon and Huber (1990). The area of open water had decreased to

Table 4

The evolution of the mixed layer and its properties after 150 days in the warm regime in the Weddell Sea for different initial and boundary conditions

\begin{tabular}{llllllllll}
\hline$H_{1}$ & $T_{\mathrm{a}}\left({ }^{\circ} \mathrm{C}\right)$ & $S_{1}$ & $t_{\mathrm{c}}(\mathrm{d})$ & $t_{\mathrm{m}}(\mathrm{d})$ & $d(\mathrm{~m})$ & $H_{1}(\mathrm{~m})$ & $\begin{array}{l}Q_{\mathrm{e}} \\
\left(\mathrm{W} \mathrm{m} \mathrm{m}^{-2}\right)\end{array}$ & $\begin{array}{l}Q_{\mathrm{a}} \\
\left(\mathrm{W} \mathrm{m} \mathrm{m}^{-2}\right)\end{array}$ & $S_{1}$ \\
\hline 20 & -20 & 34.11 & 59 & $\mathrm{a}$ & $0.06^{\mathrm{b}}$ & $60^{\mathrm{b}}$ & $109^{\mathrm{b}}$ & $108^{\mathrm{b}}$ & $34.54^{\mathrm{b}}$ \\
40 & -20 & 34.11 & 129 & 163 & $0.25^{\mathrm{b}}$ & $96^{\mathrm{b}}$ & $69^{\mathrm{b}}$ & $69^{\mathrm{b}}$ & $34.54^{\mathrm{b}}$ \\
60 & -20 & 34.11 & $*$ & $*$ & 0.45 & 106 & 50 & 50 & 34.505 \\
80 & -20 & 34.11 & $*$ & $*$ & 0.63 & 115 & 39 & 40 & 34.492 \\
80 & -25 & 34.11 & $*$ & $*$ & 0.73 & 119 & 45 & 46 & 34.505 \\
80 & -20 & 34.21 & $*$ & $*$ & 0.50 & 122 & 46 & 46 & 34.515
\end{tabular}

Gordon and Huber 1990

$68-13$

34.11

0.55

111

41

41

$34.4-5$

Note: The wind velocity is in all cases $5 \mathrm{~m} \mathrm{~s}^{-1}$. The symbols are as in the main text and in Table 2 . The properties estimated by Gordon and Huber (1990) are also shown.

${ }^{a}$ Not enough ice was formed to recreate a mixed layer of depth $H_{0}$.

${ }^{\mathrm{b}}$ The conditions just before the convection. 

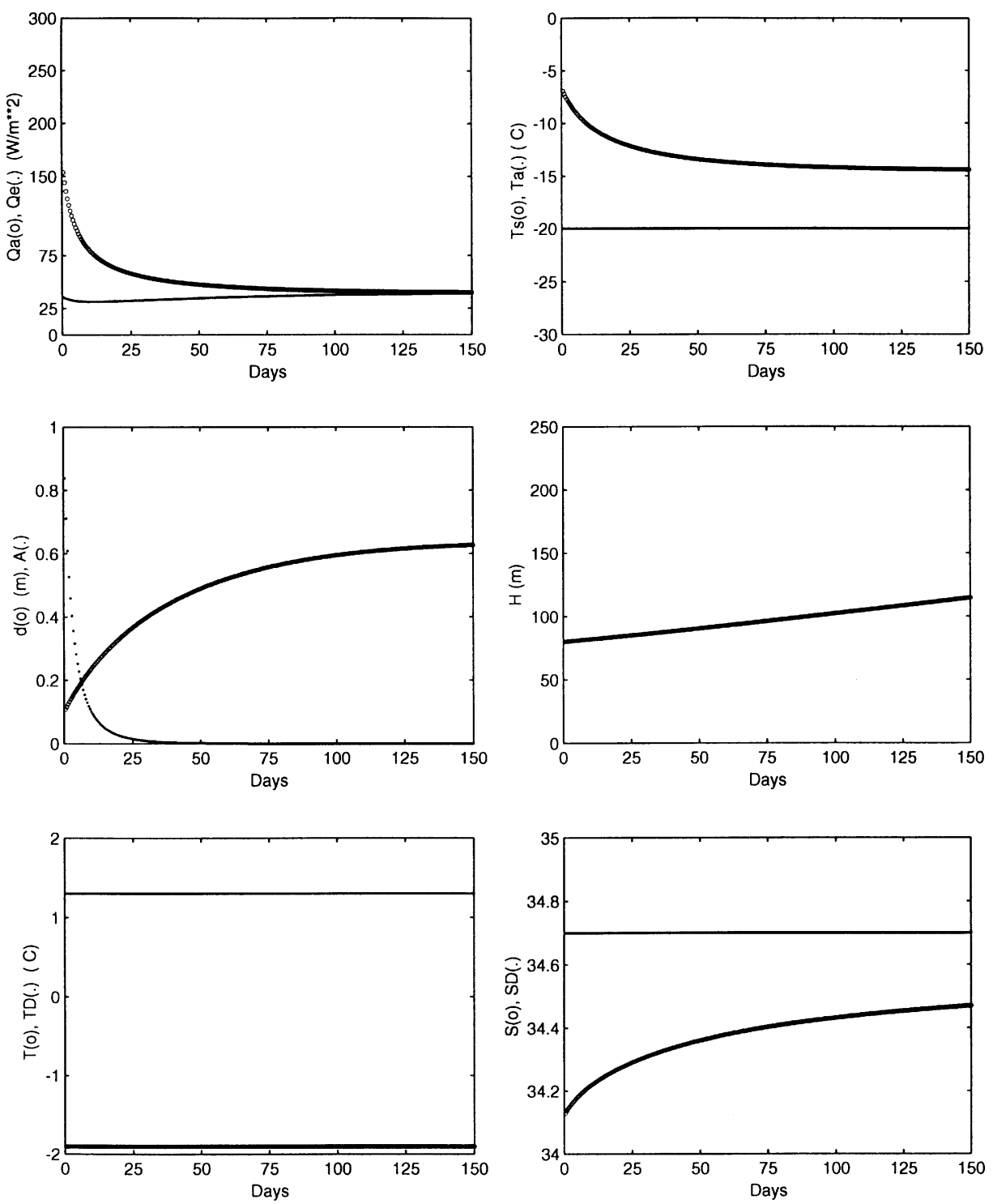

Fig. 5. The same as for Fig. 5, but with properties representative of the "warm" regime in the Weddell Sea; $T=-1.9^{\circ} \mathrm{C}, S=34.11, T_{\mathrm{D}}=1.3^{\circ} \mathrm{C}, S_{\mathrm{D}}=34.7, U_{\mathrm{a}}=5 \mathrm{~m} \mathrm{~s}^{-1}, T_{\mathrm{a}}=-20^{\circ} \mathrm{C}, H=80 \mathrm{~m}$.

zero in all non-convecting cases in contrast to the about $5 \%$ open water that has been observed in the region throughout the winter (Gordon and Huber, 1990).

Gordon and Huber (1990) estimated the amount of water entrained into the mixed layer from observations of oxygen saturation and used this to quantify the oceanic heat flux to the mixed layer and the subsequent heat loss to the atmosphere. They 
applied an empirical expression for the heat loss through the ice to compute the air temperature needed to conduct the heat through the ice with no net melting. They found this temperature to be $-13^{\circ} \mathrm{C}$, which agreed with the mean observed air temperature. The $T_{\mathrm{a}}$ we use is an "effective" air temperature, which also includes the radiation heat loss, and we should compare the $-13^{\circ} \mathrm{C}$ found by Gordon and Huber with the ice surface temperature $T_{\mathrm{s}}$. This is about $6^{\circ} \mathrm{C}$ higher than $T_{\mathrm{a}}$ and for $T_{\mathrm{a}}=-20^{\circ} \mathrm{C} T_{\mathrm{s}}-14^{\circ} \mathrm{C}$ (Fig. 5, 2nd panel).

At Maud Rise the second layer is considerably colder $\left(-0.5^{\circ} \mathrm{C}\right)$ and less saline (34.6). Also here 6 different situations were examined. Four cases had a mixed-layer depth of $80 \mathrm{~m}$, mixed-layer salinities of 34.21 and 34.31, and air temperatures of $-20^{\circ} \mathrm{C}$ and $-25^{\circ} \mathrm{C}$. In the last two cases the mixed-layer depth was $120 \mathrm{~m}$, the salinity 34.31 and the air temperatures -20 and $-25^{\circ} \mathrm{C}$. The stability in all cases but one was removed by the end of the winter (150 days) and convection did occur (Table 5). However, this happened late in winter, and no polynya would have time to develop before the summer ice melt. The increase in mixed-layer depth up to the first convection event was between 25 and $50 \mathrm{~m}$. The maximum ice thickness, occurring just before the convection, was between 40 and $75 \mathrm{~cm}$ and the entrained heat between 35 and $60 \mathrm{~W} \mathrm{~m}^{-2}$ (Table 5). No balance between heat loss to the atmosphere and entrained heat was reached before the convection, and net ice formation still took place.

For the shallow, high salinity case with the smallest heat loss the first instability occurred after 80 days and the mixed layer was reformed 18 days later (Fig. 6). A second convection event took place after 162 days, and again a mixed layer was reformed. After a third convection event the ice finally disappeared after 205 days and a polynya was created. For the case with a higher heat loss, four convective events took place before the ice had disappeared. This occurred after 171 days, slightly longer than the estimated winter duration. The fraction of open water exceeded $50 \%$ between the last two convection events and a polynya could be considered formed before the last convection. These results indicate that deep convection may occur at Maud Rise, but to create a polynya the initial salinity of the mixed layer must be high.

Table 5

The evolution of the mixed layer at Maud Rise for different initial and boundary conditions

\begin{tabular}{rrrrrrlllll}
\hline$H_{1}(\mathrm{~m})$ & $T_{\mathrm{a}}\left({ }^{\circ} \mathrm{C}\right)$ & $S_{1}$ & $t_{\mathrm{c}}(\mathrm{d})$ & $d(\mathrm{~m})$ & $H_{1}$ & $\begin{array}{l}Q_{\mathrm{e}} \\
\left(\mathrm{W} \mathrm{m}^{-2}\right)\end{array}$ & $\begin{array}{l}Q_{\mathrm{a}} \\
\left(\mathrm{W} \mathrm{m} \mathrm{m}^{-2}\right)\end{array}$ & $S_{1}$ & $N$ & $t_{\mathrm{m}}(\mathrm{d})$ \\
\hline 80 & -20 & 34.21 & 160 & 0.61 & 164 & 41 & 41 & 34.53 & 4 & 394 \\
80 & -25 & 34.21 & 101 & 0.66 & 139 & 48 & 49 & 34.53 & 5 & 313 \\
80 & -20 & 34.31 & 80 & 0.43 & 132 & 51 & 51 & 34.53 & 3 & 205 \\
80 & -25 & 34.31 & 50 & 0.47 & 116 & 59 & 62 & 34.53 & 4 & 171 \\
120 & -20 & 34.31 & 137 & 0.68 & 183 & 37 & 38 & 34.53 & 4 & 406 \\
120 & -25 & 34.31 & 87 & 0.72 & 169 & 42 & 46 & 34.53 & 3 & 324 \\
\hline
\end{tabular}

Note: The wind velocity is $5 \mathrm{~m} \mathrm{~s}^{-1}$ in all cases. The symbols are as in the main text and in Table 2 . 

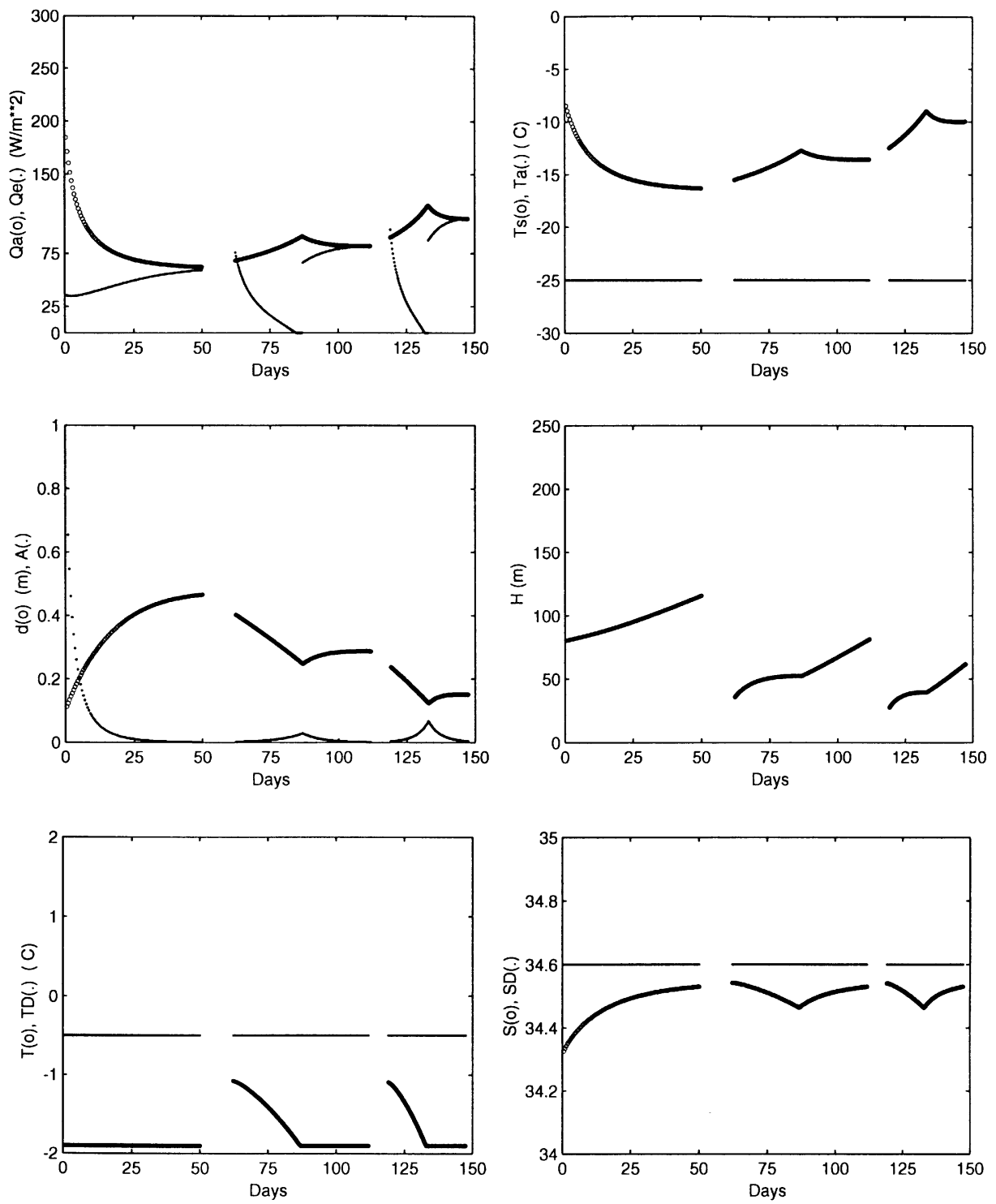

Fig. 6. The same as Fig. 5, but with properties representative of Maud Rise, $S=34.31, T=-1.9^{\circ} \mathrm{C}$, $S_{\mathrm{D}}=34.6, T_{\mathrm{D}}=-0.5^{\circ} \mathrm{C}, U_{\mathrm{a}}=5 \mathrm{~m} \mathrm{~s}^{-1}, T_{\mathrm{a}}=-25^{\circ} \mathrm{C}, H=80 \mathrm{~m}$.

\subsection{The Greenland Sea}

The $\Theta-S$ characteristics of the Greenland Sea water column show that a renewal of the bottom water can occur through local convection. Several deep (1000-2000 m) convection events have been observed in recent years (GSP group, 1990), but no 
convection reaching the bottom has been documented in the time period 1982-1996. The water column in the Greenland Sea is also influenced by waters advected from the Arctic Ocean and by Atlantic Water recirculating in Fram Strait and returning along the Greenland continental slope. The Atlantic Water lies immediately below the low salinity mixed layer. It is prominent closer to the rim, colder and often absent in the centre. The Arctic Ocean outflow supplies both ice and low-salinity surface water as well as deep waters. The deep waters of the Arctic Ocean are warmer and more saline than the deep waters formed in the Greenland Sea.

Roach et al. (1993) reported temperature, salinity and current measurements from instruments moored for one year in the central Greenland Sea and in "Isodden" north of Jan Mayen. They found that in the central Greenland Sea the mixed layer, after it had reached freezing temperature and ice was forming, convected after about $1 \frac{1}{2}$ months. Two to three weeks later the ice cover had disappeared. The interpretation given by Roach et al. (1993) was that the density of the upper layer in the central gyre had increased due to released brine, and that it convected into the deeper layers. Warmer water was brought close to the surface, melting the ice. The new low-salinity layer was then assumed advected from the central gyre. Deep, thermal convection was established and continued for the rest of the winter.

Visbeck (1993) and Visbeck et al. (1995) studied the same area and period using observations from moored thermistor chains and ADCPs, and applied a one-dimensional mixed-layer model forced by real meteorological data. To reproduce the observed changes in the mixed layer they found that a net export of $0.005 \mathrm{~m} \mathrm{~d}^{-1}$ of ice out of the area was required, about $1 / 3$ of ice production estimated by Roach et al. (1993). From model calculations Visbeck et al. (1995) concluded that the entrainment from below became so strong that the ice started to melt before the mixed layer convected. After the ice cover was removed a deep thermal convection was established.

We shall examine two situations, where the second layer is dominated by Atlantic and Arctic waters $\left(T_{\mathrm{D}}=-0.4^{\circ} \mathrm{C}\right.$ and $\left.T_{\mathrm{D}}=-1.4^{\circ} \mathrm{C}\right)$, respectively. The initial salinities of the mixed layer are set to 34.656 and 34.631 , and $T_{\mathrm{a}}=-25^{\circ} \mathrm{C}$ and $U_{\mathrm{a}}=7 \mathrm{~m} \mathrm{~s}^{-1}$ are used for the atmospheric forcing. The salinities of the second layer are 34.88 and 34.855 , respectively, making the stratification in the Arctic situation about $30 \%$ more stable. Until now only the effects of the characteristics of underlying waters on the ice cover and the mixed layer evolution have been considered. However, the second layer has a finite thickness, which may be more important in the Greenland Sea, with several sources of intermediate waters, than in the Weddell Sea. We therefore also discuss the effects of the convection events on the second layer. Based upon the results of the Greenland Sea Project (GSP group, 1990; Roach et al., 1993; Schott et al., 1993; Visbeck et al., 1995) it is assumed that the two upper layers together

Fig. 7. The same as for Fig. 5, but with a finite depth $H_{\mathrm{D}}$ of the second layer and properties representative of the Greenland Sea. The evolution of the second layer salinity, $S_{\mathrm{D}}$ and temperature, $T_{\mathrm{D}}\left({ }^{\circ} \mathrm{C}\right)$ is also shown (panels 5 and 6). $\left(H+H_{\mathrm{D}}\right)=600 \mathrm{~m}, U_{\mathrm{a}}=7 \mathrm{~m} \mathrm{~s}^{-1}, T_{\mathrm{a}}=-25^{\circ} \mathrm{C}$. (a) $T=-1.9^{\circ} \mathrm{C}, S=34.656$, $\Delta \rho^{\prime}=0.119 \mathrm{~kg} \mathrm{~m}^{-3}, T_{\mathrm{D}}=-0.4^{\circ} \mathrm{C}, S_{\mathrm{D}}=34.88, f_{\mathrm{w}}=0.345$. (b) $T=-1.9^{\circ} \mathrm{C}, S=34.631, \Delta \rho^{\prime}=0.159 \mathrm{~kg}$ $\mathrm{m}^{-3}, T_{\mathrm{D}}=-1.4^{\circ} \mathrm{C}, S_{\mathrm{D}}=34.855, f_{\mathrm{w}}=1.035$. 
make up $600 \mathrm{~m}$ of the water column, and we follow the evolution of the second layer as well as the mixed layer. The mixed layer convects when it reaches marginal stability. After a new mixed layer of depth $H_{0}$ has formed, it is assumed that the convected water mixes completely with the remaining part of the second layer. The second layer becomes colder and fresher but retains its density. In the reformed mixed layer $f_{\mathrm{w}}$ will now be larger than $f_{0}$ because of the reduced temperature of the
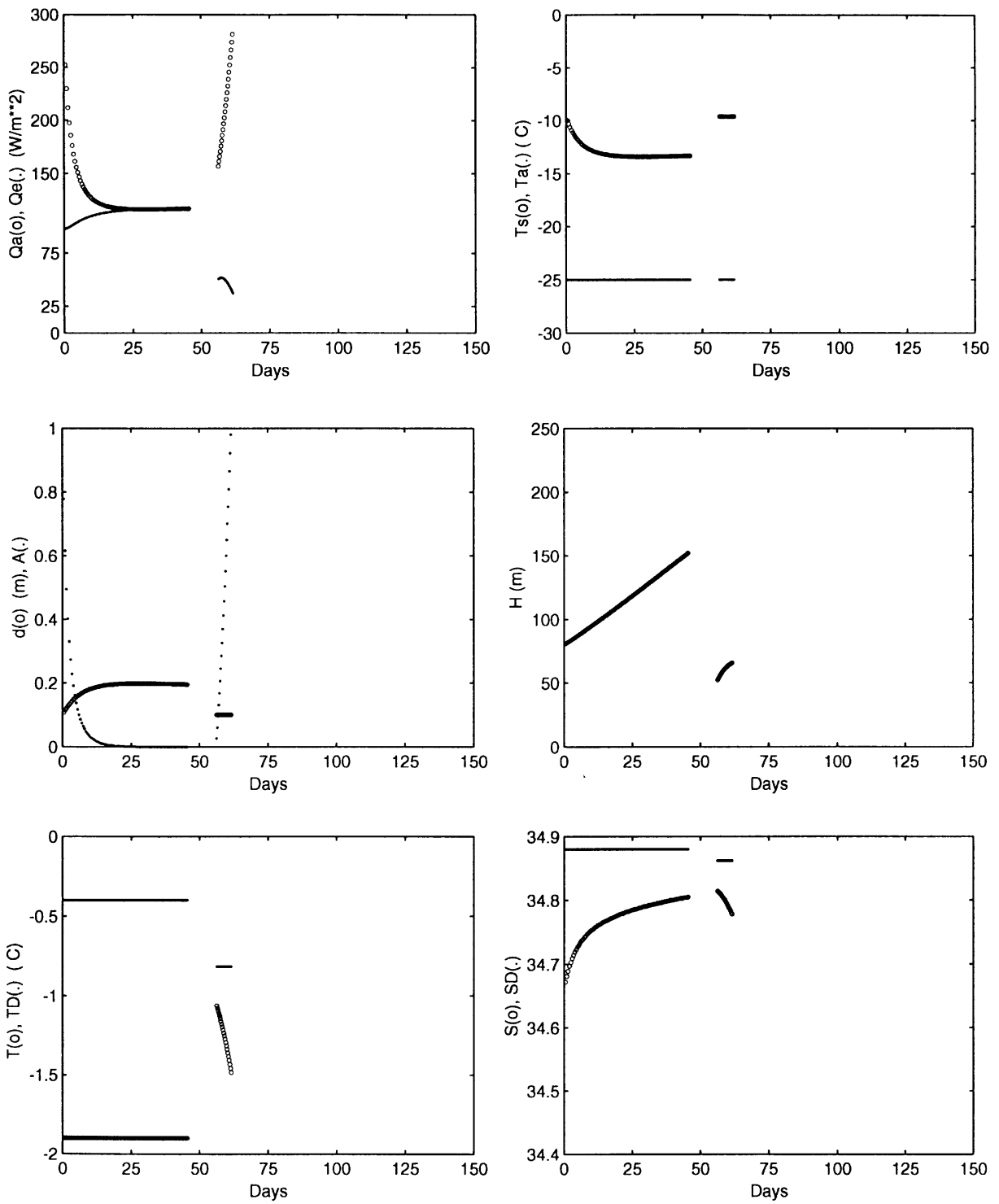

(a) 

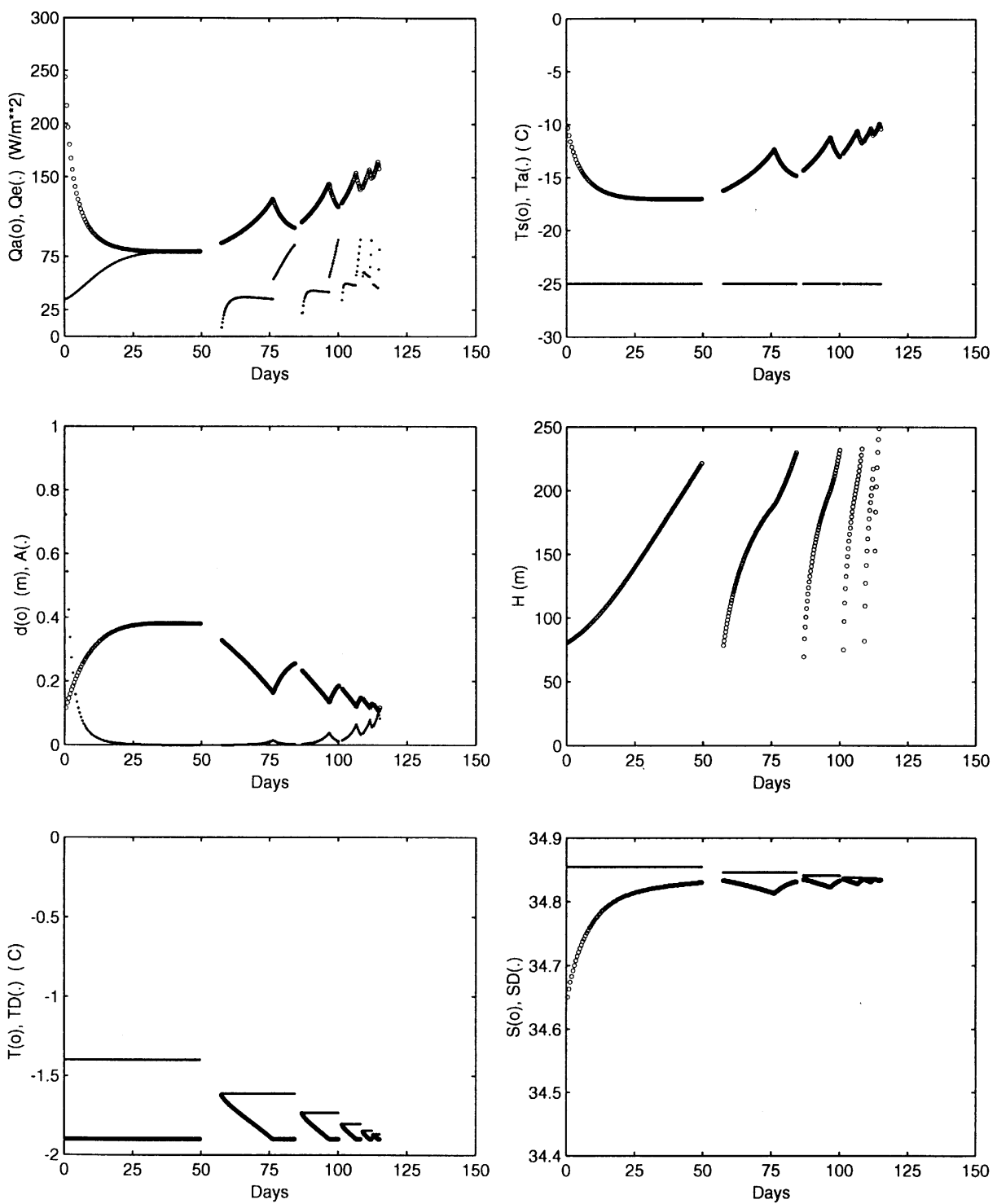

(b)

Fig. 7. Continued.

underlying water, and the changes in the second layer will affect the mixed-layer evolution.

The two cases are shown in Fig. 7a and b. The first instability and convection arise after about the same time, but a balance between heat loss to the atmosphere and entrained heat has then been reached for the "Atlantic" case, while there is still a net 
heat loss in the low-salinity colder, "Arctic" case (1st panels). After the convection the ice rapidly melts in the Atlantic situation and a mixed layer with temperatures above freezing remains. Apart from a slightly higher initial salinity this run recaptures the observations by Roach et al. (1993), and the evolution of the temperature and salinity of the two layers can be compared with those described by Roach et al. (1993). The ice formation is smaller than that estimated by Roach et al. (1993) because a large part of the salinity increase is due to entrainment of saline water from below. The freshwater input from melting after the convection is then smaller, and a local freshwater balance without export is conceivable. The freshwater is convected into the deeper layers.

In the second situation a series of convection events arises, occurring faster and faster (Fig. 7b). The heat flux from below does not go to zero between convection events, but remains at a low and constant level for a longer period before ice formation again starts (1st panel). The deepening between the convection events proceeds rapidly because of the ever weaker stability, and a mixed layer thicker than $200 \mathrm{~m}$ convects each time (4th panel). The ice thickness is reduced, but the ice has not disappeared before the density difference between the two layers is removed by the repeated injections of cold, low salinity water into the lower layer. Haline convection would then reach the base of the second layer.

Two more cases will be discussed (Fig. 8a and b). The temperature of the second layer is $-1.3^{\circ} \mathrm{C}$, but the total depths are 400 and $600 \mathrm{~m}$, respectively. The wind is reduced to $U_{\mathrm{a}}=6 \mathrm{~m} \mathrm{~s}^{-1}$, and the initial stability is weaker than in the previous situations. For the deeper second layer, four convective events occur before the ice is removed. For the shallower second layer seven convective events take place, after which the stability at the mixed layer base has practically disappeared. Ice however, is still present. A shallower second layer becomes colder by convection, and a longer phase of deep reaching haline convection is promoted.

A low-salinity, cold (but above freezing) mixed layer was observed in the winter 1987-88 after what was interpreted as a haline convection event (Rudels et al., 1989). The temperature of the mixed layer was between that of the lower layer and the freezing point, and the density step due to salinity was about twice that due to temperature. This suggests a removal of the mixed layer into the deep and the rising of the lower layer to the surface, leading to ice melt and to the reformation of a low salinity mixed layer. In 1988-89 the absence of a cold, low salinity surface layer (GSP group, 1990) indicates that the final stage of the convection was thermal as suggested by Roach et al. (1993) and Visbeck et al. (1995).

Haline convection in the Greenland Sea is then mostly confined to the upper part of the water column. Spells of deep reaching, haline convection are likely to be brief, especially if Atlantic Water dominates in the second layer. The ventilation of the deeper waters will then be caused by later, thermal convection and a deepening of the mixed layer. When the Arctic component is strongly represented, the freshwater content is large as well as the temperature low, and a situation with several convective events arises. If the second layer is cold and thin, the two layers may merge during active haline convection. The combined layer will then increase in density until still deeper convection occurs. Most likely the ice will eventually disappear also in this situation. 

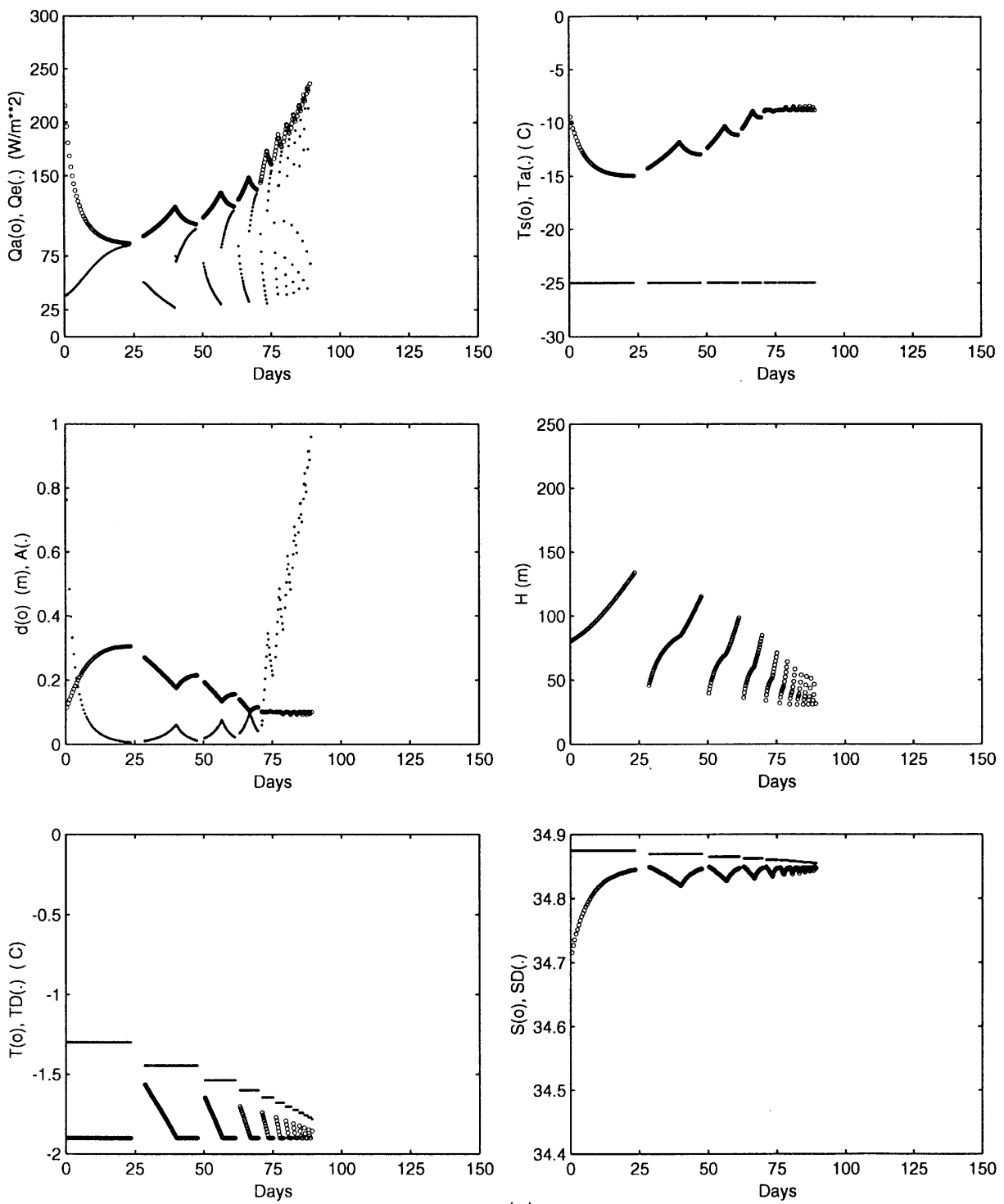

(a)

Fig. 8. The same as in Fig. 7. $T=-1.9^{\circ} \mathrm{C}, S=34.70, \Delta \rho^{\prime}=0.116 \mathrm{~kg} \mathrm{~m}^{-3}, T_{\mathrm{D}}=-1.3^{\circ} \mathrm{C}, S_{\mathrm{D}}=34.875$, $f_{\mathrm{w}}=0.669, U_{\mathrm{a}}=6 \mathrm{~m} \mathrm{~s}^{-1}, T_{\mathrm{a}}=-25^{\circ} \mathrm{C}$. (a) $\left(H+H_{\mathrm{D}}\right)=600 \mathrm{~m},(\mathrm{~b})\left(H+H_{\mathrm{D}}\right)=400 \mathrm{~m}$.

\section{Summary}

The present work examines whether deep convection, driven by brine rejection, is possible in the ocean. It is found that within the context of energy balance mixed-layer models, this depends upon how the loss of oceanic sensible heat is distributed between 

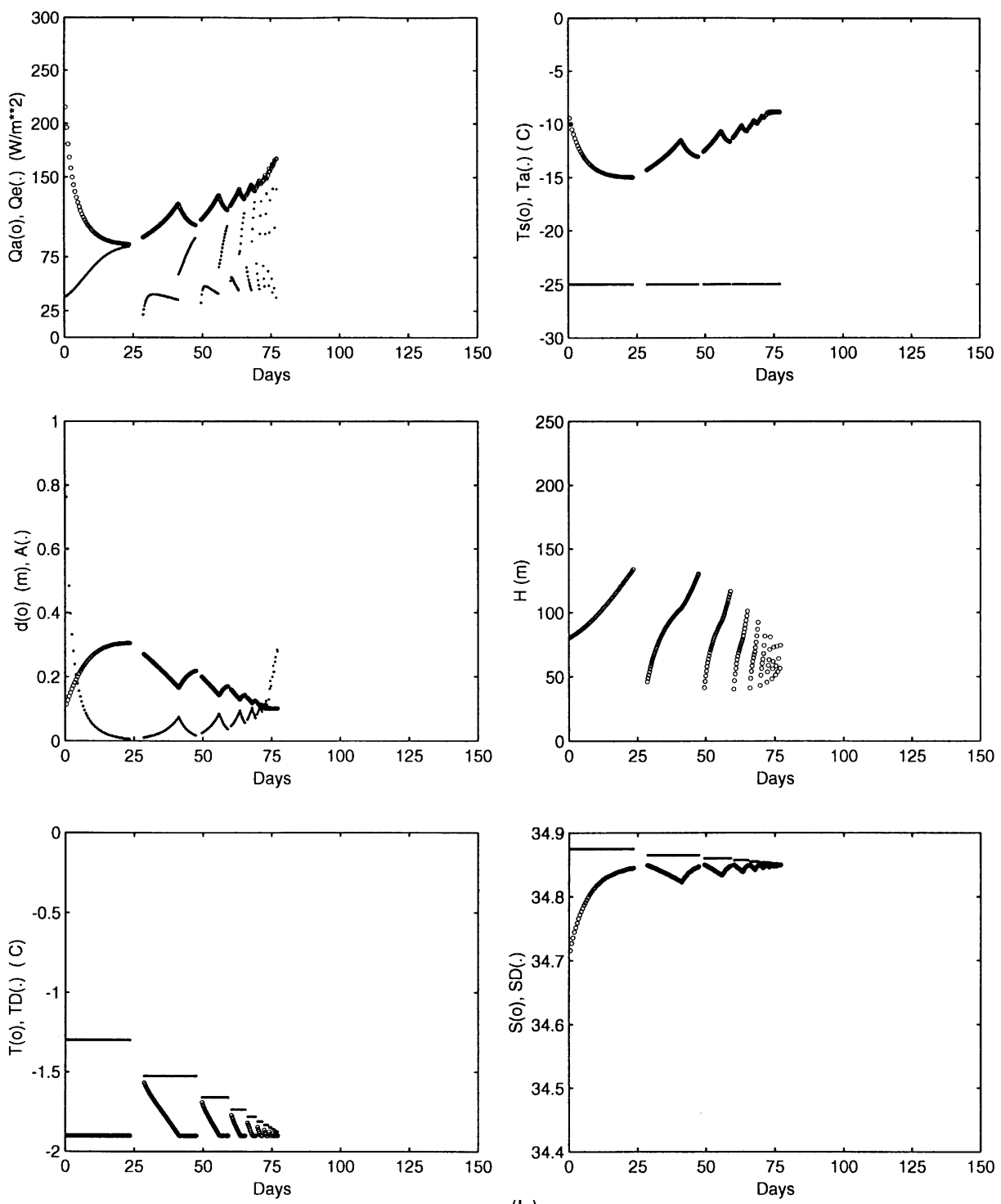

(b)

Fig. 8. Continued.

atmosphere and ice melt. If a constant fraction goes to ice melt, or if the partitioning has a minimum value larger than $f_{0} / 2$, the stability at the base of the mixed layer will disappear and the mixed layer convect before the ice is melted.

Is this realistic? This assumption could be questionable, when the stability is weak and the ice cover thin and large areas of open water are present. This is also when the 
model studies by Walin (1993) and Visbeck et al. (1995) indicate the removal of the ice. Because the stability of the mixed layer decreases with ice formation, it is expected that the heat flux from below, which depends inversely on the stability, eventually provides more heat than is required by the atmosphere. However, melting increases the stability and lowers the entrainment rate, and freezing may again be needed to supply enough heat to the atmosphere, thus pushing the system toward renewed freezing. Therefore, assuming that melting occurs, what is the maximum stability, or the maximum freshwater content, the mixed layer must have to unequivocally sustain melting?

If we write the entrainment equation in the form used by Walin (1993), taking into account a net buoyancy input due to melting we get

$$
w_{\mathrm{e}}=\frac{2 m_{0} u_{*}^{3}}{g\left(\beta \Delta_{\mathrm{D}} S-\alpha \Delta_{\mathrm{D}} T\right) H}-\frac{g\left(\frac{\left(Q_{\mathrm{e}}-Q_{\mathrm{a}}\right) c L^{-1} \beta S}{\rho c}-\frac{\alpha Q_{\mathrm{e}}}{\rho c}\right)}{g\left(\beta \Delta_{\mathrm{D}} S-\alpha \Delta_{\mathrm{D}} T\right)} .
$$

The heat available for melting can be written as

$$
\left(Q_{\mathrm{e}}-Q_{\mathrm{a}}\right)=w_{\mathrm{e}} c \rho \Delta_{\mathrm{D}} T\left(1-\frac{Q_{\mathrm{a}}}{w_{\mathrm{e}} c \rho \Delta_{\mathrm{D}} T}\right) .
$$

Inserting this into the expression for the entrainment velocity given above and making the same rearrangement as in Section 2 we get

$$
w_{\mathrm{e}}=\frac{m_{0} u_{*}^{3}\left(1+f_{\mathrm{w}} \frac{c}{L} \Delta_{\mathrm{D}} T\right)}{g \alpha \Delta_{\mathrm{D}} T\left(\left(\left(1-\frac{Q_{\mathrm{a}}}{w_{\mathrm{e}} c \rho \Delta_{\mathrm{D}} T}\right)+f_{\mathrm{w}}\right) \frac{c \beta S_{\mathrm{D}}}{2 \alpha L}-\left(1+f_{\mathrm{w}} \frac{c}{L} \Delta_{\mathrm{D}} T\right)\right) H} .
$$

If we now solve for $w_{\mathrm{e}}$ and introduce $\Delta_{\mathrm{D}} T$, the expression for the entrained heat flux becomes

$$
\begin{aligned}
w_{\mathrm{e}} \Delta_{\mathrm{D}} T= & \frac{Q_{\mathrm{e}}}{\rho c} \\
= & \frac{m_{0} u_{*}^{3}\left(1+f_{\mathrm{w}} \frac{c}{L} \Delta_{\mathrm{D}} T\right)}{g \alpha\left(\left(1+f_{\mathrm{w}}\right) \frac{c \beta S_{\mathrm{D}}}{2 \alpha L}-\left(1+f_{\mathrm{w}} \frac{c}{L} \Delta_{\mathrm{D}} T\right)\right) H} \\
& +\frac{Q_{\mathrm{a}}}{\rho c\left(1+\left(f_{\mathrm{w}}-\frac{2 \alpha L}{c \beta S_{\mathrm{D}}}\left(1+f_{\mathrm{w}} \frac{c}{L} \Delta_{\mathrm{D}} T\right)\right)\right)} .
\end{aligned}
$$

The bracket in the denominator of the second term is $<0$, if $f_{\mathrm{w}}<f_{0}$. This means that the heat flux from below must be larger than the heat loss to the atmosphere, if the 
freshwater content in the mixed layer is so small that the stabilising density step due to salinity is less than twice the destabilising density step due to temperature. To obtain this we do not have to consider the first term as long as it is positive. This is in agreement with the test cases considered in Section 4, where smaller fractions than $f_{0}$ were examined. It also agrees with the results obtained by Walin (1993).

However, to deduce that deep convection is not possible also requires the assumption that no ice is formed at all once the melting stage is reached. This is far more difficult to prove, theoretically as well as observationally, given all possibilities of how the atmosphere-ice-mixed layer-ocean system may interact. One could argue that a large amount of open water would make it easier for the entrained heat to avoid melting ice and escape to the atmosphere. On the other hand, open water will favour new ice production, and even if the ice is rapidly melted, a larger portion of the entrained heat then goes to ice melt than the difference between entrained heat and heat lost to the atmosphere indicates. The buoyancy input due to this added ice melt would inhibit the entrainment enough to allow convection to start before the ice cover is removed.

We have assumed that a preferred fraction $f_{0}$ of sensible heat going to ice melt exists, and have examined if this assumption leads to obvious contradictions with observational facts. This does not appear to be the case. We believe that the value obtained for $f_{0}$ is of the right order (see discussion in Section 2.1). The description of entrainment and ice cover has, on purpose, been kept simple (one could even say retrograde, as was pointed out by one reviewer). This is partly not to obscure our main goal, to study the effects of the chosen distribution of the heat flux. It also eases the comparison with the studies by Walin (1993) and Visbeck et al. (1995). Many of the possible improvements of the energy balance mixed-layer model, which can be made, would actually favour freezing rather than entrainment and melting. Another assumption is that wind-mixed entrainment is a larger obstacle to deep, haline convection than the entrainment caused by the convection itself. This is the commonly accepted view, but it could be wrong, especially if the mixed layer is deep. The model by Backhaus (1995) does imply that brine-driven, haline convection may shut itself off.

If deep haline convection does occur, a goal would be to combine a more sophisticated mixed layer description with a plume convection model. The results from the situations studied in the Greenland Sea (Section 4.3) indicate that recurrent convective events transform the second layer, making it colder and less saline. In that description the convecting water was not denser than that of the second layer and its density did not increase. In reality convective plumes must be slightly denser, and the cooling of the second layer will, because of the higher compressibility of colder water, also reduce the density step at the lower boundary of the second layer. In the situation with remaining ice and haline convection breaking through the mixed layer, the plumes may continue through the second layer. Haline plumes start with temperature at the freezing point, and because only cold water is entrained in the mixed layer as well as the second layer, the thermobaric effect on the plumes will be strong, when they reach the lower boundary of the second layer. They may then have a large enough positive density anomaly to sink into the deep ocean, perhaps by-passing some levels and reach the bottom layer. In the case of thermal convection the initial density anomalies 
are smaller, the temperature higher and the thermobaric effect at the lower boundary will be smaller, even if a deep ( > $2000 \mathrm{~m}$ ) mixed layer exists as in 1989 (GSP-group, 1990).

These are, at present, idle speculations that require more thorough investigations. However, this work is already long enough and introduces hypotheses that may appear counter intuitive. It is therefore not the place to introduce another, controversial, subject, and we end the present study here.

\section{Acknowledgements}

We wish to thank Norbert Verch for technical assistance. This work has partly been supported by the European Commission MAST II programme ESOP-I (MAS2CT93-0057). Economic support for one of us (BR) has been received from the Deutsche Forschungsgemeinschaft (DFG-SFB-18, TP B3) and from the European Commission MAST III Programme VEINS, through contract MAS3-CT96-0070.

\section{Appendix A. List of symbols}

$A \quad$ area of open water (fraction)

$A_{\mathrm{m}} \quad$ minimum area of open water (fraction)

$B \quad$ buoyancy flux to the mixed layer, $\mathrm{Wkg}^{-1}$

$C_{\mathrm{D}} \quad$ drag coefficient $\left(1.1 \times 10^{-3}\right)$

E evaporation, $\mathrm{m}$

$D \quad$ thickness of layer by-passed by the convection, $\mathrm{m}$

$F_{(1)} \quad$ ice removed by freezing, $\mathrm{m}$

$H \quad$ depth of the mixed layer, $\mathrm{m}$

$H_{0} \quad$ depth of equilibrium mixed layer for which $Q_{\mathrm{a}}=(1-f) Q_{\mathrm{e}}, \mathrm{m}$

$I \quad$ volume of ice formed in open water, $\mathrm{m}$

$K \quad$ Newtonian transfer coefficient, $1.43 \mathrm{~J}^{\circ} \mathrm{C}^{-1} \mathrm{~m}^{-3}$

$L \quad$ latent heat of melting, $335 \times 10^{3} \mathrm{~J} \mathrm{~kg}^{-1}$

$L_{\mathrm{e}} \quad$ loss of latent heat to the atmosphere, $\mathrm{W} \mathrm{m}^{-2}$

$L_{\mathrm{v}} \quad$ latent heat of evaporation $\left(2.50 \times 10^{6} \mathrm{~J} \mathrm{~kg}^{-1}\right)$

$M_{(1)} \quad$ ice melt, $\mathrm{m}$

$P \quad$ precipitation, $\mathrm{m}$

$Q \quad$ oceanic loss of sensible heat, $\mathrm{W} \mathrm{m}^{-2}$

$Q_{\mathrm{a}} \quad$ heat loss to the atmosphere, $\mathrm{Wm}^{-2}$

$Q_{\text {sa }} \quad$ loss of sensible heat to the atmosphere, $\mathrm{W} \mathrm{m}^{-2}$

$Q_{\mathrm{i}} \quad$ heat loss to the atmosphere through the ice, $\mathrm{W} \mathrm{m}^{-2}$

$Q_{0} \quad$ heat loss at the open sea surface, $\mathrm{W} \mathrm{m}^{-2}$

$Q_{\mathrm{e}} \quad$ heat entrained from the lower layer, $\mathrm{W} \mathrm{m}^{-2}$

$S \quad$ salinity of the mixed layer

$S_{\mathrm{D}} \quad$ salinity of the lower layer 
$S_{\mathrm{i}} \quad$ salinity of sea ice

$S^{\prime} \quad$ salinity fluctuations

$T$ temperature of the mixed layer, ${ }^{\circ} \mathrm{C}$

$T_{\mathrm{D}} \quad$ temperature of the lower layer, ${ }^{\circ} \mathrm{C}$

$T_{\mathrm{f}} \quad$ freezing temperature $\left(-1.9^{\circ} \mathrm{C}\right)$

$T_{\mathrm{a}} \quad$ air temperature, ${ }^{\circ} \mathrm{C}$

$T_{\mathrm{s}} \quad$ temperature of ice surface, ${ }^{\circ} \mathrm{C}$

$T^{\prime} \quad$ temperature fluctuations, ${ }^{\circ} \mathrm{C}$

$U_{\mathrm{a}} \quad$ wind speed, $\mathrm{ms}^{-1}$

$b \quad$ buoyancy, $\mathrm{ms}^{-2}$

$c \quad$ heat capacity of sea water $\left(=3.98 \times 10^{6} \mathrm{~J} \mathrm{~kg}^{-10} \mathrm{C}^{-1}\right)$

$c_{\mathrm{p}} \quad$ heat capacity of air $\left(=1.0 \times 10^{3} \mathrm{~J} \mathrm{~kg}^{-10} \mathrm{C}^{-1}\right)$

$d \quad$ ice thickness, $\mathrm{m}$

$d_{0} \quad$ prescribed initial ice thickness $(=0.1 \mathrm{~m})$

$f \quad$ fraction of oceanic heat going to ice melt

$f_{0} \quad$ fraction of oceanic heat leading to minimum ice melt rate

$f_{\mathrm{w}} \quad$ normalised fresh water content in the mixed layer

$g \quad$ acceleration of gravity $\left(=9.8 \mathrm{~m} \mathrm{~s}^{-2}\right)$

$k_{\mathrm{t}} \quad$ thermal diffusivity of water $\left(=1 \times 10^{-3} \mathrm{~m}^{2} \mathrm{~s}^{-1}\right)$

$m_{0} \quad$ dissipation factor $(=1.25)$.

$q_{\mathrm{a}} \quad$ specific humidity of air

$q_{\mathrm{w}} \quad$ saturated specific humidity of air

$r \quad f^{\prime}\left(f_{0}\right)^{-1}$

$t \quad$ time, $\mathrm{s}$

$t_{0} \quad$ time needed to reform the equilibrium mixed layer, $\mathrm{s}$

$t_{\mathrm{c}} \quad$ time to first convection, $\mathrm{d}$

$t_{\mathrm{m}} \quad$ time until the ice is melted, $\mathrm{d}$

$u_{*} \quad$ friction velocity, $\mathrm{m} \mathrm{s}^{-1}$

$v \quad$ ice volume, $\mathrm{m}$

$v_{\mathrm{m}} \quad$ maximum ice volume, $\mathrm{m}$

$w_{\mathrm{e}} \quad$ entrainment velocity, $\mathrm{m} \mathrm{s}^{-1}$

$w^{\prime} \quad$ vertical velocity fluctuations, $\mathrm{m} \mathrm{s}^{-1}$

$\overline{w^{\prime} T^{\prime}} \quad$ turbulent heat transport

$\overline{w^{\prime} S^{\prime}} \quad$ turbulent salt transport

$\alpha \quad$ coefficient of heat expansion $\left(=0.4 \times 10^{-4}\right)$

$\beta \quad$ coefficient of salt contraction $\left(=8.0 \times 10^{-4}\right)$

$\delta \quad$ freshwater content in the mixed layer, $\mathrm{m}$

$\varepsilon \quad$ buoyancy parameter $(\varepsilon=1$ when $B>0, \varepsilon=0.05$ when $B<0)$

$\kappa_{\mathrm{i}} \quad$ coefficient of heat conduction through ice $\left(=2.0^{\circ} \mathrm{C}^{-1} \mathrm{~m}^{-1} \mathrm{~s}^{-1}\right)$

$\lambda \quad$ scale factor used during ice melt, $\mathrm{m}^{-1}$

$\rho_{0}=\rho$ density of freshwater $\left(=1000 \mathrm{~kg} \mathrm{~m}^{-3}\right)$

$\rho_{\mathrm{w}} \quad$ density of water $\left(=1028 \mathrm{~kg} \mathrm{~m}^{-3}\right)$

$\rho_{\mathrm{a}} \quad$ density of air $\left(=1.3 \mathrm{~kg} \mathrm{~m}^{-3}\right)$

$\rho_{\mathrm{i}} \quad$ density of ice $\left(=910 \mathrm{~kg} \mathrm{~m}^{-3}\right)$

$\Delta \rho^{\prime} \quad$ density step at the base of the mixed layer 


\section{References}

Backhaus, J.O., 1995. Prozeßstudien zur Ozeanischen Konvektion. Habilitationsabhandlung der Universität Hamburg, 112 pp.

Defant, A., 1961. Physical Oceanography, Vol. I. Pergamon Press, Oxford, 729 pp.

Farmer, D.M., 1975. Penetrative convection in the absence of mean shear. Quarterly Journal of Royal Meteorological Society 101, 861-891.

Gade, H.G., 1993. When ice melts in sea water: a review. Atmosphere-Ocean 31, 139-165.

Gill, A.E., 1973. Circulation and bottom water production in the Weddell Sea. Deep-Sea Research 20, 111-140.

Gordon, A.L., 1978. Deep Antarctic convection west of Maud Rise. Journal of Physical Oceanography 10, $600-612$.

Gordon, A.L., Huber, B.A., 1990. Southern Ocean mixed layer. Journal of Geophysical Research 95, 11655-11673.

GSP group, 1990. Greenland sea project: A venture toward improved understanding of the oceans' role in climate. Eos 71, 750-751 and 754-755.

Hibler III, W.D., 1979. A dynamic thermodynamic sea ice model. Journal of Physical Oceanography 9, $815-846$.

Hibler III, W.D., Flato, G.M., 1992. Sea ice models. In: Trenberth, K.E. (Ed.), Climate system modelling. Cambridge University Press, Cambridge, pp. 413-450.

Houssais, M.-N., 1988. Testing a coupled ice-mixed-layer model under subarctic conditions. Journal of Physical Oceanography 18, 196-210.

Houssais, M.-N., Hibler III, W.D., 1993. Importance of convective mixing in seasonal ice margin simulations. Journal of Geophysical Research 98, 16427-16448.

Kato, H., Phillips, O.M., 1969. On the penetration of a turbulent layer into a stratified fluid. Journal of Fluid Mechanics 37, 643-655.

Killworth, P.D., 1979. On chimney formations in the oceans. Journal of Physical Oceanography 9, 531-554.

Killworth, P.D., 1983. Deep convection in the world ocean. Revue of Geophysics and Space Physics 21, $1-26$.

Lemke, P., 1987. A coupled one-dimensional sea ice-ocean model. Journal of Geophysical Research 92, 13164-13172.

Lemke, P., Owens, W.B., Hibler III, W.D., 1991. A coupled sea-ice mixed layer-pycnocline model for the Weddell Sea. Journal of Geophysical Research 95, 9513-9525.

Martinson, D.G., 1990. Evolution of the Southern Ocean winter mixed layer and sea ice: open ocean deep water formation and ventilation. Journal of Geophysical Research 95, 11641-11654.

Martinson, D.G., Killworth, P.D., Gordon, A.L., 1981. A convective model of the Weddell Polynya. Journal of Physical Oceanography 11, 466-488.

Niiler, P.P., Kraus, E.B., 1977. One-dimensional models of the upper ocean. In: Kraus, E.B. (Ed.), Modeling and prediction of the upper layers of the ocean. Pergamon Press, Oxford, pp. 143-179.

Parkinson, C.L., Washington, W.M., 1979. A large-scale numerical model of sea ice. Journal of Geophysical Research 84, 311-337.

Roach, A.T., Aagaard, K., Carsey, F.D., 1993. Coupled ice-ocean variability in the Greenland Sea. Atmosphere-Ocean 31, 319-337.

Rudels, B., 1990. Haline convection in the Greenland Sea. Deep-Sea Research 37, 1491-1511.

Rudels, B., 1993. High latitude ocean convection. In: Stone, D.B., Runcorn, S.K. (Eds.), Flow and Creep in the Solar System: Observations, Modeling And Theory. Kluwer Academic Publishers, Dordrecht, pp. 323-356.

Rudels, B., Quadfasel, D., Friedrich, H., Houssais, M.-N., 1989. Greenland Sea convection in the winter of 1987-1988. Journal of Geophysical Research 94, 3223-3227.

Schott, F., Visbeck, M., Fischer, J., 1993. Observations of vertical currents and convection in the central Greenland Sea during the winter of 1988-1989. Journal of Geophysical Research 98, 14402-14421.

Smith, W.O. (Ed.), 1990. Polar Oceanography, Part A, Physical Sciences. Academic Press, New York, $406 \mathrm{pp}$. 
Untersteiner, N. (Ed.), 1986. The Geophysics of Sea Ice. Plenum Press, New York, 1196 pp.

Visbeck, M., 1993. Konvektion im offenen Ozean. Berichte aus dem Institut für Meereskunde an der Christian-Albrecht-Universität, Kiel, Nr 237, 187 pp.

Visbeck, M., Fischer, J., Schott, F., 1995. Preconditioning the Greenland Sea for deep convection: ice formation and ice drift. Journal of Geophysical Research 100, 18489-18502.

Walin, G., 1993. On the formation of ice on deep weakly stratified water. Tellus 45A, 143-157.

Washington, W.M., Parkinson, C.L., 1986. An Introduction to Three-Dimensional Climate Modeling. University Science Books, Mill Valley, 422 pp.

Zwally, H.J., Comiso, J.C., Parkinson, C.L., Campbell, W.J., Carsey, F.D., Gloersen, P., 1983. Antarctic Sea Ice, 1973-1976: Satellite Passive-Microwave Observation. NASA, Washington, DC, 206 pp. 